Florida International University FIU Digital Commons

FIU Electronic Theses and Dissertations

University Graduate School

7-13-2012

\title{
Predictors of Success: Medical Laboratory Associate in Science Degree Program
}

Nilia M. Madan

Florida International University, nilia.madan@gmail.com

DOI: $10.25148 /$ etd.FI12073002

Follow this and additional works at: https://digitalcommons.fiu.edu/etd

\section{Recommended Citation}

Madan, Nilia M., "Predictors of Success: Medical Laboratory Associate in Science Degree Program" (2012). FIU Electronic Theses and Dissertations. 672.

https://digitalcommons.fiu.edu/etd/672

This work is brought to you for free and open access by the University Graduate School at FIU Digital Commons. It has been accepted for inclusion in FIU Electronic Theses and Dissertations by an authorized administrator of FIU Digital Commons. For more information, please contact dcc@fiu.edu. 


\title{
FLORIDA INTERNATIONAL UNIVERSITY
}

Miami, Florida

\section{PREDICTORS OF SUCCESS: MEDICAL LABORATORY ASSOCIATE IN SCIENCE DEGREE PROGRAM}

\author{
A dissertation submitted in partial fulfillment of the \\ requirements for the degree of \\ DOCTOR OF EDUCATION \\ in
}

ADULT EDUCATION AND HUMAN RESOURCE DEVELOPMENT

by

Nilia M. Madan

2012 
To: Dean Delia C. Garcia

College of Education

This dissertation, written by Nilia M. Madan, and entitled Predictors of Success: Medical Laboratory Associate in Science Degree Program, having been approved in respect to style and intellectual content, is referred to you for judgment.

We have read this dissertation and recommend that it be approved.

\begin{tabular}{rr}
\hline Eric Brewe \\
\hline Glenda D. Musoba \\
\hline Lynn Ilon \\
\hline Thomas G. Reio, Jr., Major Professor
\end{tabular}

Date of Defense: July 13, 2012

The dissertation of Nilia M. Madan is approved.

Dean Delia C. Garcia

College of Education

Dean Lakshmi N. Reddi University Graduate School

Florida International University, 2012 
(C) Copyright 2012 by Nilia M. Madan

All rights reserved. 


\section{DEDICATION}

I dedicate this dissertation to the two most important people in my life, my husband of thirty-two years, and my daughter. My husband has been my partner through the years and has supported me in all my endeavors with love and always a helping hand. He learned how to cook, and took care of all the chores around the house so I could devote my time to finishing this dissertation. He has encouraged me and picked me up when I thought I could not continue. Finishing this dissertation has truly been a difficult journey and having my husband's love and support made all the difference.

My daughter is a beautiful young woman and a wonderful mother. I thank her for her love and encouragement when I had all but given up ever finishing this dissertation. She was the one that said, "no mom you cannot give up now, you are so close. Contact the professors you know and see if they want to be on your committee." It was her wisdom at that moment that set me on the right path to move forward and finish this dissertation. I also want to thank my granddaughter who although too young to read this dedication, is the light of my life who fills my world with love and laughter. 


\section{ACKNOWLEDGMENTS}

I want to thank the members of my committee for their commitment to assisting me through this process. I want to especially thank Dr. Thomas G. Reio and Dr. Lynn Ilon. Dr. Reio for agreeing to chair my committee and for taking me under his wing and guiding me through the maze of data. Dr. Ilon for answering the e-mail four years ago and agreeing to be on my committee. You took me by the hand, introduced me to Dr. Reio and helped me with getting my initial ideas down on paper. I know I would not have been able to complete this dissertation without the dedication and support of my committee members.

Finally, I want to thank my parents especially my father. Although he is no longer here, he was always an example of perseverance, and truly a lifelong learner who never stopped reading and writing poetry. His example inspired me to love learning from an early age. 


\title{
ABSTRACT OF THE DISSERTATION \\ PREDICTORS OF SUCCESS: MEDICAL LABORATORY \\ ASSOCIATE IN SCIENCE DEGREE PROGRAM
}

\author{
by
}

Nilia M. Madan

Florida International University, 2012

Miami, Florida

\section{Professor Thomas G. Reio, Jr., Major Professor}

Hospitals and healthcare facilities in the United States are facing serious shortages of medical laboratory personnel, which, if not addressed, stand to negatively impact patient care. The problem is compounded by a reduction in the numbers of academic programs and resulting decrease in the number of graduates to keep up with the increase in industry demands. Given these challenges, the purpose of this study was to identify predictors of success for students in a selected 2-year Medical Laboratory Technology Associate in Science Degree Program.

This study examined five academic factors (College Placement Test Math and Reading scores, Cumulative GPA, Science GPA, and Professional [first semester laboratory courses] GPA) and, demographic data to see if any of these factors could predict program completion. The researcher examined academic records for a 10 -year period $(N=158)$. Using a retrospective model, the correlational analysis between the variables and completion revealed a significant relationship $(p<.05)$ for CGPA, SGPA, CPT Math, and PGPA indicating that students with higher CGPA, SGPA, CPT Math, and PGPA were more likely to complete their degree in 2 years. Binary logistic regression analysis 
with the same academic variables revealed PGPA was the best predictor of program completion $(p<.001)$.

Additionally, the findings in this study are consistent with the academic part of the Bean and Metzner Conceptual Model of Nontraditional Student Attrition which points to academic outcome variables such as GPA as affecting attrition. Thus, the findings in this study are important to students and educators in the field of Medical Laboratory Technology since PGPA is a predictor that can be used to provide early in-program intervention to the at-risk student, thus increasing the chances of successful timely completion. 


\section{TABLE OF CONTENTS}

CHAPTER

PAGE

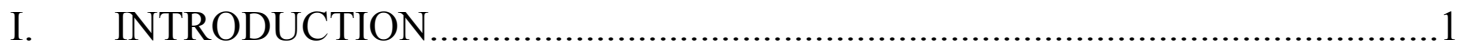

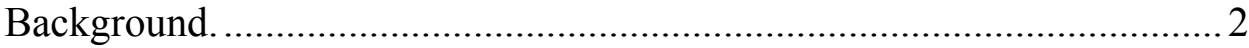

Conceptual Framework ...................................................................... 4

Background on Variables Related to Attrition............................................ 8

Statement of the Problem....................................................................... 10

Purpose of the Study............................................................................ 14

Research Question and Subquestions. ..................................................... 14

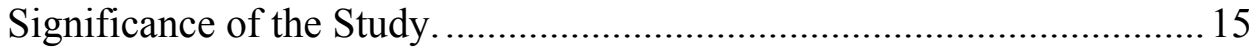

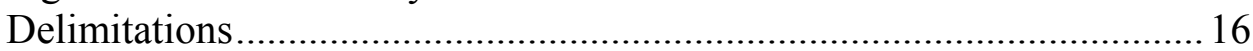

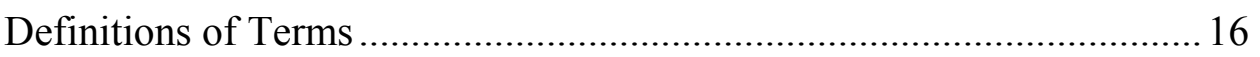

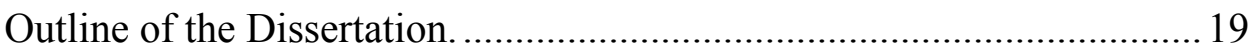

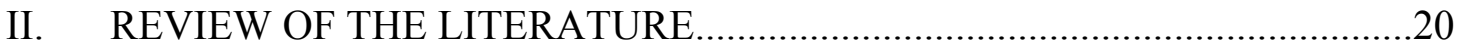

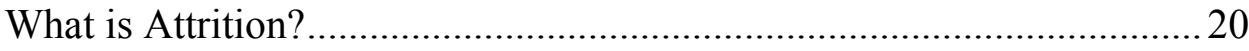

Empirical Studies in Health Sciences and Nursing Programs ..................29

Medical Laboratory Technology................................................................. 31

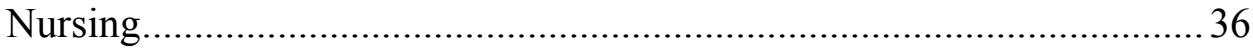

Health Sciences.............................................................................. 45

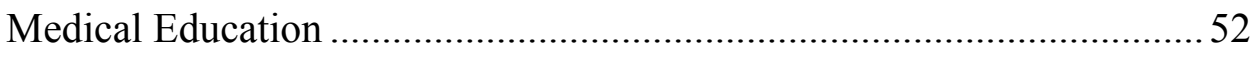

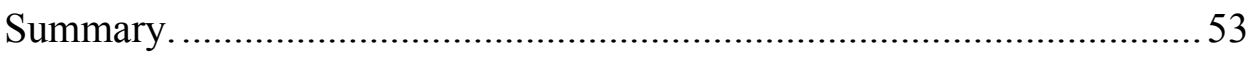

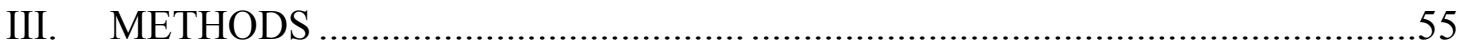

Sample

Research Measures...............................................................................57

ACCUPLACER/Computerized Placement Test (CPT) ……................57

Cumulative GPA, Science GPA, Professional GPA.............................58

Dependent Variable: Program Completion.........................................5 59

Independent Variables: Cumulative GPA (CGPA) ..................................59

ACCUPLACER/Computerized Placement Test CPT Scores.................60

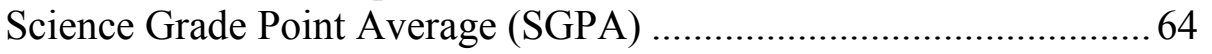

Professional GPA After First Semester (PGPA) ……………...............65

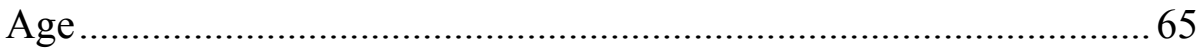

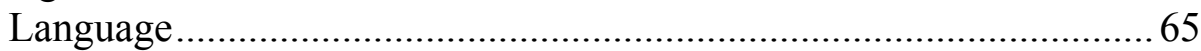

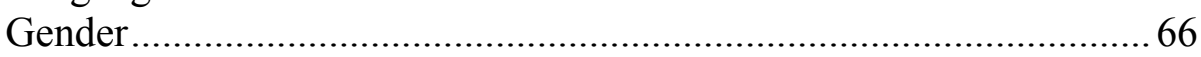

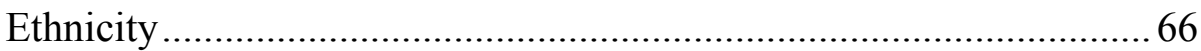

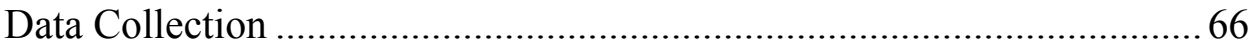

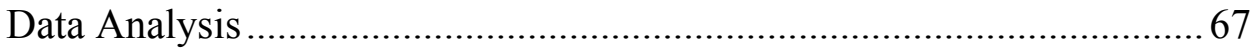

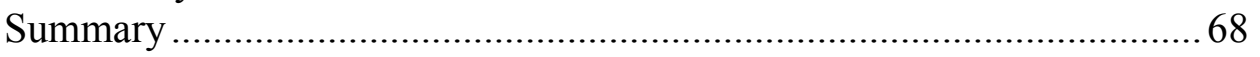




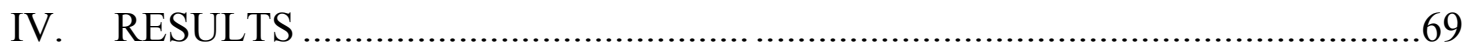

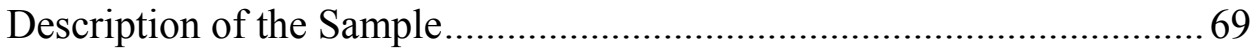

Analysis of the Variables ...................................................................... 70

Description of the Demographic and Academic Variables......................... 70

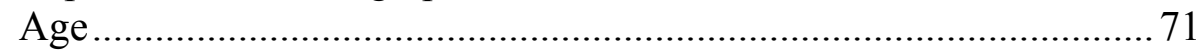

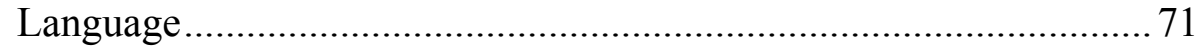

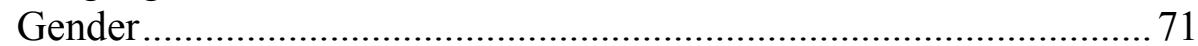

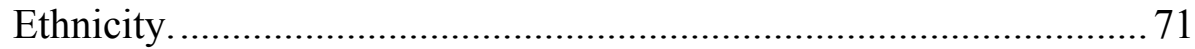

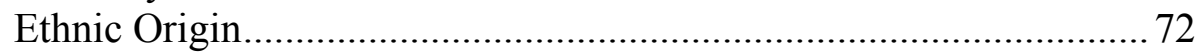

Cumulative GPA (CGPA) ........................................................... 72

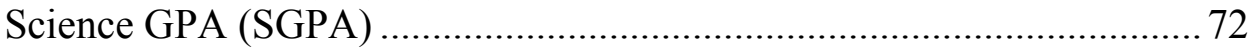

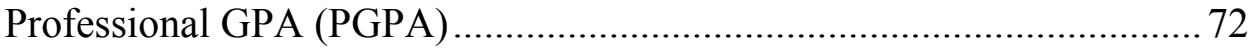

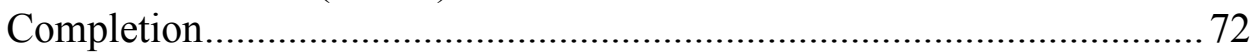

Time to Completion ................................................................................. 73

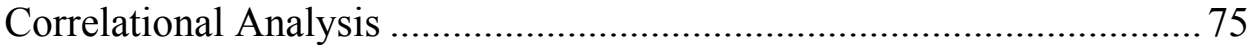

Group Mean Differences..................................................................... 77

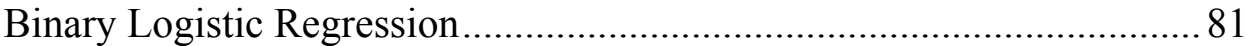

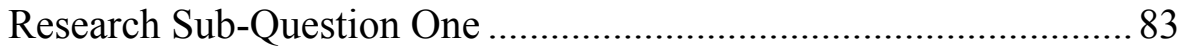

Research Sub-Question Two.............................................................. 84

Research Sub-Question Three............................................................. 85

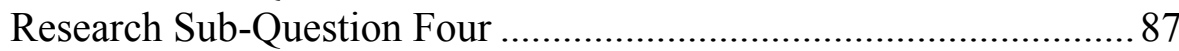

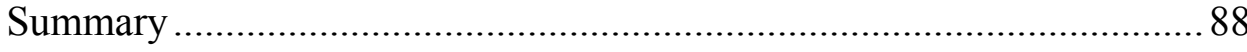

V. SUMMARY, CONCLUSIONS, RECOMMENDATIONS …………………......90

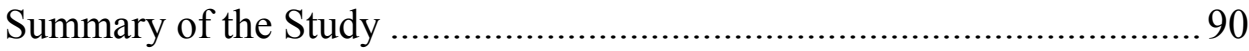

Research Sub-Question One .......................................................... 92

Research Sub-Question Two...........................................................95

Research Sub-Question Three............................................................96

Research Sub-Question Four ..............................................................97

Recommendations for Future Research ................................................. 98

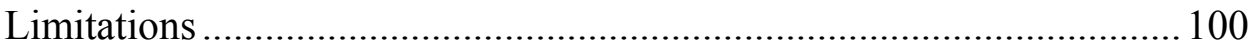

Implications for Future Research............................................................ 101

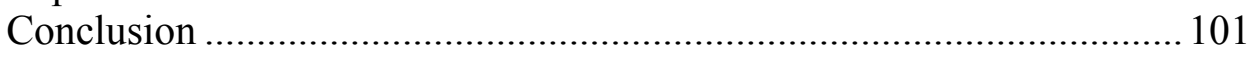

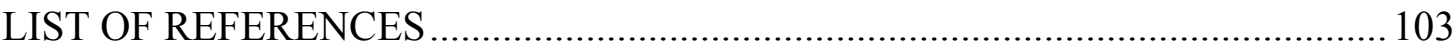

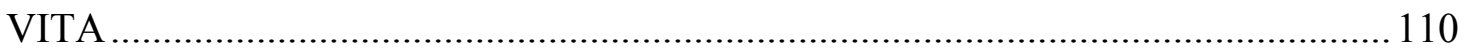




\section{LIST OF TABLES}

TABLE

PAGE

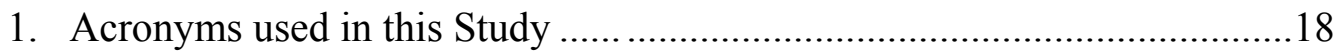

2. ACCUPLACER College Placement Guide Reading and Writing ............. 63

3. ACCUPLACER College Placement Guide Math ...................................63

4. Descriptive Statistics for Academic Variables CGPA, SGPA, PGPA ........ 73

5. Frequency Table for Demographic Variable ....................................... 73

6. Demographic Variables Cross Tabulation........................................... 75

7. Correlation Coefficients for Completion, Time to Completion

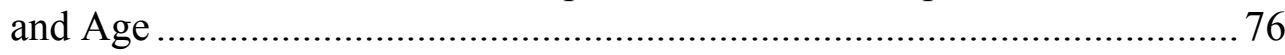

8. Analysis of Variance of Group Mean Differences by Age........................ 77

9. Three-Way Analysis of Variance Results for Research Variables ..............79

10. Summary of Logistic Regression Analysis of Academic Independent Variables Predicting Completion in Research Sub-Question One .84

11. Summary of Logistic Regression Analysis for Demographic Independent Variables Predicting Completion in Research Sub-Question Two

12. Summary of Logistic Regression Analysis of Variables Predicting the Extent to which Performance on CPT Math and Reading Predicted Completion in Research Sub-Question Three.

13. Summary of Logistic Regression Analysis of Variables Predicting the Extent to which Cumulative GPA, Science GPA, and Professional GPA Predicted Program Completion in Research Sub-Question Four .88 


\section{CHAPTER I}

\section{INTRODUCTION}

This dissertation addressed the problem of attrition in clinical laboratory science (CLS) educational programs. While this problem is nationwide, the study focuses on the problem with an A.S. degree program in Florida. Cearlock, the CEO of the National Accrediting Agency for Clinical Laboratory Sciences (as cited in Enrado, 2009), indicated "the current vacancy rate in the clinical laboratory sciences field is $13 \%$ " (p. 1). Furthermore, according to Cearlock (as cited in Enrado, 2009), "in the next 5 years, 13\%

of the workforce is expected to retire, with $25 \%$ of the workforce retiring over the next 10 years" (p. 1). Cearlock (as cited in Enrado, 2009) asserted that "the situation is compounded by the facts that only two new clinical lab professionals enter the field for every seven who retire, and the average age of the laboratory professional is over 50" (p. 1). In fact, Hilborne (2008) reported in his President's Perspective that the profession will need 81,000 technologists and technicians to replace laboratory professionals that will retire by 2014. Facing this national shortage of educational opportunities and the projected need for laboratory professionals, faculty and trained professionals found it was more critical than ever to make sure that entrants to the program succeeded, graduated, and prepared to enter the profession. This research study looked at factors that contributed to attrition for students entering into an A.S. degree Medical Laboratory Technology (MLT) program. The study sought to determine which student-level variables contributed to predicting student graduation from the program. The study examined the College Placement Test (CPT) math, and reading scores, cumulative GPA, science GPA, and first-semester program GPA as predictors of graduation. 


\section{Background}

The clinical laboratory profession has its roots in clinical pathology. In fact, "the practice of modern medicine would not be possible without the professional services of medical technologists, also known as clinical laboratory scientists" Muelhlenkamp (as cited in Kirby, 2007).

According to Kotlarz (1998)

most histories of clinical laboratory science (CLS) either follow the development of laboratory testing from its rudimentary beginnings in ancient times, or they begin in the mid-1920s, when the American Society of Clinical Pathologists established the Board of Registry to regulate training programs and determine minimum qualifications of clinical laboratory practitioners. (p. 5)

Since 1933, the field of clinical laboratory science has evolved and changed. In the $21^{\text {st }}$ Century, clinical laboratory science is a healthcare profession that encompasses areas such as hematology, clinical chemistry, microbiology, parasitology, immunohematology, toxicology, immunology, and molecular pathology. The clinical laboratory workforce is comprised of practitioners nationally recognized by their degree of education and training as well as by their level of expertise. It is the combination of education, training, and experience, which differentiates practitioners and qualifies them for employment in a particular field. Holladay (2008) reported on the more than 420,000 certifications that have been awarded since the establishment of the American Registry of Medical Technicians, its former name. Holladay's report also pointed to the original core objective for the BOR, which is "to establish a pathway that would increase the competence of laboratory workers through a process of certification" (p. 2). Programs in 
clinical laboratory science, whether at a community college or a university, must prepare students to work in an environment where they will be evaluating data from diverse sources and making decisions that will ultimately impact patient care. Students who apply to these programs are typically persons who are interested in science and who want to be a part of the healthcare field in a profession with limited patient contact. The characteristics necessary to be successful in a clinical laboratory science program include a strong science background in chemistry, biology, and anatomy and physiology in addition to mathematics. Students must also bring strong written and verbal communication skills to be successful at their general education courses, which include college-level English, social science, psychology, critical thinking, and ethics. These courses are part of the curriculum and with the science courses, comprise the general education core of the degree.

At both the A.S. and the B.S. level, programs in Florida employ faculty with years of clinical experience in all disciplines and the requisite graduate degrees necessary to teach in higher education. These faculty members must be nationally certified and licensed by the Florida Department of Health. The faculty engage in teaching, accreditation, advisement, curriculum, and career development.

Often, students come to the program with most of the general education coursework completed. In fact, criteria for program selection require that students complete required courses in English and either anatomy and physiology or chemistry before applying to the program. Additionally, students must also have attained a minimum GPA of 2.0. Attrition rates for clinical laboratory programs are always a 
concern. It is not unusual that out of 35 students starting the fall term, only 15 to 20 will ultimately complete the program and graduate within the prescribed 2-year curriculum.

This study was conducted within a Medical Laboratory Technology program at an urban college in the State of Florida. The sponsoring institution had a total enrollment of approximately 170,000 students and was unique because of the diversity of its student population. The college where the study was conducted had one campus dedicated to the Health Sciences and Nursing. Within the School of Health Sciences, there are 13 A.S. degree medical programs and six vocational certificate programs. One of those thirteen A.S. medical programs was Medical Laboratory Technology.

According to the MDC Fact Book (2012) "Miami Dade College has the largest undergraduate enrollment of any U.S. college or university, with more than 174,000 students, and the largest Hispanic student enrollment" (p. 1). In fact, the MDC Fact Book also reports "MDC students represent 185 countries and speak 94 different languages" (p. 2). However, the uniqueness of the student population did not stop with its language diversity because the MDC Fact Book also reports that "Sixty-one percent of [the] students attend part-time, and the average age is $26 "$ (p. 1). Close examination of that same report indicated that, "69 percent work while attending college, and 20 percent work full time" (MDC Fact Book, 2012, p. 2).

\section{Conceptual Framework}

This study was based on the Bean and Metzner (1985) Conceptual Model of Nontraditional Student Attrition. From a historical perspective, Tinto's (1975) theoretical model of dropout behavior is rooted in the concept that dropping out is a longitudinal process that embodies certain conditions within the social and academic realm that, when 
combined, lead to attrition. According to Tinto (1975), his theoretical model of dropout behavior

argues that the process of dropout from college can be viewed as a longitudinal process of interactions between the individual and the academic and social systems of the college during which a person's experiences in those systems (as measured by his normative and structural integration) continually modify his goal and institutional commitments in ways which lead to persistence and/or to varying forms of dropout. (p. 94)

Tinto's (1975) model takes into consideration the students' demographic characteristics as well as pre-college experiences. These variables include grade point average and attainments in the academic and social realms with the expectation that these parameters and others, such as family background, will exert a direct or indirect effect on the students' college performance. In fact, Tinto (1975) posited that, "given individual characteristics, prior experiences, and commitments, ...it is the individual's integration into the academic and social systems of the college that most directly relates to his continuance in college” (p. 96). While Tinto's theory is considered the basis for future research in attrition, it does not address the unique circumstances of the commuter and non-traditional student. In fact, Tinto's early work examined student populations of traditional students in 4-year institutions. This may be partly due to the fact that Tinto's first study was conducted in 1973 during a period when a high percentage of students were high school graduates in their late teens, either living on campus or living at home with the parents and unemployed. Thus, Tinto's early work does not focus on the commuter student who does not live on-campus and because of the responsibilities of 
work and family, often does not become integrated into the social fabric of the college. However, by the 1980s and into the 1990s, the focus had changed from the traditional student in a 4-year institution to the non-traditional commuter student in a community college setting. It is during this period in 1997 that Tinto published his study examining the community college classroom and its role as a learning community where students engaged with faculty and with each other with the goal of enhancing the teaching and learning experience. Tinto (1997) indicated that "this research...sheds important light on how interactions across the academic and social geography of a campus shape the educational opportunity structure of campus life, in turn, both student learning and persistence" (p. 619).

The Bean and Metzner Model of Nontraditional Student Attrition published in 1985, traced the history of attrition research up to 1985 and brought in the community college factor as a higher education phenomenon that exploded after World War II (Bean $\&$ Metzner, 1985). With this increase in commuter 2-year institutions, a whole new set of students began to appear on the higher education scene. These students termed as "nontraditional," came with social and academic characteristics that differed from the more “traditional" students addressed in Tinto's (1975) model. From this realization, Bean and Metzner began to define this set of students and considered their unique characteristics into a model that could be used to predict non-traditional student persistence. The author's definition of the non-traditional student included demographic characteristics, such as differences in age as well as the realization that from a social perspective, these students were more mature and thus less susceptible to the socialization factor previously described in models using a more traditional student population. 
In the development of their model, Bean and Metzner (1985) were influenced by the contributions of Spady (1970), Tinto, (1975), and Pascarella and Terenzini (1980). In their research, Bean and Metzner found that "one defining characteristic of the nontraditional student was the lack of social integration into the institution; therefore, a different theory must be used to link the variables in the model" (p. 489).

The Bean and Metzner (1985) model defined dropout decisions as based on four sets of variables (academic, background, environmental, and psychological). According to Bean and Metzner, "GPA is based primarily on past [high school] academic performance" (p. 490). However, in this study cumulative GPA was a measure of not only past high school academic performance but also college performance on prerequisite coursework completed prior to starting the program of study. Conversely, CPT scores were more of a measure of background high school knowledge in math and reading. First semester GPA and Science GPA, while not included in the Bean and Metzner (1985) model, were more relevant in this study than high school performance when examining an older student population. In fact, these parameters provided a unique look at some of the variables that may be predictors when using a diverse population of students in a healthcare program that relies heavily on prior knowledge in important scientific areas. Other demographic factors such as age and ethnicity were also examined in this study. 


\section{Background on Variables Related to Attrition}

Variables associated with attrition in this study are levels of academic preparation as represented by cumulative GPA (CGPA), level of science preparation as represented by science GPA (SGPA), score on the Accuplacer College Placement Test (CPT), and GPA after the first semester in the Medical Laboratory Technology Program (Professional GPA, PGPA).

The predictive value of cumulative GPA (CGPA) has been extensively examined in studies and used as a measure of student success. In fact, cumulative GPA forms part of the selection criteria for entrance to academic programs in the healthcare field as well as in other academic fields of study. Researchers such as Houltram (1996), Potolsky (2003), Hopkins (2008), have studied the importance of examining grade point average in their studies. According to Houltram (as cited in Potolsky, 2003) "age and entry qualifications had a relationship to future academic success" (p. 246).

Other researchers in the nursing field, such as Newton, Smith, Moore, (2007), found that "preadmission GPA and TEAS [Aptitude Test] were significant predictors of variance in first semester GPA" (p. 147). Moreover Newton et al. found that of the two measures (preadmission GPA and the TEAS Aptitude Test), preadmission GPA was a better predictor of first semester GPA. This supported not only the use of the variable CGPA as a possible predictor in this study but also the use of first semester GPA (or Professional GPA) as a variable. In fact, Newton et al. found that "scholastic aptitude and nursing aptitude are useful predictors of early academic achievement" (p. 147).

Other studies using more global populations of students have also examined entrance exams, such as SAT scores and first quarter GPA, in looking at retention 
patterns. A study conducted by Murtaugh, Burns, and Schuster (1999) examined the retention of 8,867 undergraduate students at Oregon State University between 1991 and 1996 to determine retention using precollege characteristics, such as high school GPA, SAT scores, First Quarter GPA, demographic variables, and other variables. These other variables included residency, college at first enrollment, enrollment in Freshman Orientation Course, and participation in education opportunities program.

According to Reason (2003), a review of the research on persistence conducted by Peltier, Laden, and Matranga (1999) cited many student background variables that directly affect the probability that a student will persist in college. In fact, according to an analysis by Peltier et al., gender, race and ethnicity, socioeconomic status, high school grade point average, college grade point average, as well as the interaction between these variables are related to persistence. (p. 177)

An eminent study in nursing that pointed to variables used in this study was the Wong and Wong (1999) research, which examined the contribution of basic sciences and success in nursing program courses. Wong and Wong's study pointed to the importance of cumulative GPA (CGPA) and success in the biological and physical sciences as well as in nursing coursework as significant predictors of success when examining pass rates on national licensure examinations. In fact, Wong and Wong explained, that "the majority of published studies indicate that basic sciences are significant predictors of student success within the nursing curriculum" (p. 346). While this predictor has been studied within the nursing student population, it has never been studied in the medical technology student population, which formed the basis for using science GPA (SGPA) 
and first semester professional GPA (PGPA) as predictors in this study. Moreover, with both the Tinto (1975) and the Bean and Metzner (1985) model, integration into the fabric of the academic institution is key to persistence. Therefore, by examining first semester professional GPA (PGPA) the researcher looked at the student population after completion of one semester in the program.

\section{Statement of the Problem}

Hospitals and healthcare facilities in the U.S. are facing critical shortages of medical laboratory personnel, which, if not addressed, stand to negatively affect the quality of patient care. The scope of the problem confronting healthcare institutions is multifaceted. According to the 2009 Wage and Vacancy Survey for Clinical Laboratories Nearly one-half of the clinical laboratories across the nation report experiencing difficulties hiring personnel. Western states struggle more with recruitment compared to other regions of the country, as notably fewer labs report success in filling positions within six months. Shortages were reported for all the laboratory positions surveyed, but vacancy rates for certified medical technologists and histotechnicians were particularly high, at 10.4\% and 8.0\% respectively. (ASCP e-Policy News, p. 1)

In 2006, the Bureau of Labor Statistics reported employment levels for clinical laboratory technicians and technologists at 319,000. Their projection for personnel needs nationwide are expected to reach 362,000 by 2016 , representing a $14 \%$ increase in the employment needs for the U.S in the coming years. In fact, the 2006 Bureau of Labor 
Statistics reported that the job opportunities for clinical laboratory personnel are expected to grow because the number of job openings will continue to exceed the number of job seekers. In the most recent report from the Bureau of Labor Statistics in 2010, the report reflected that the employment outlook for medical technologists and technicians was expected to grow by $11 \%$ between 2010 and 2020 , with a $13 \%$ average growth for the profession. This translates into an employment change for the 10-year period of 42,900 jobs. This increase in the number of laboratory professionals needed is compounded by the problem of the aging American "baby boomer" population (born between 1945 and 1962) and their consequential increased need for healthcare services.

The number of examinees for MLT in any one year is a reflection of the number of graduates. According to the U.S. Department of Health and Human Services, in 1970, there were 791 Medical Technology (MT) programs nationwide. By 2003, the number had dropped to 240 , a $70 \%$ decrease. Likewise, the number of medical laboratory technology (MLT) programs nationwide had declined from 281 programs in 1985 to 210 programs in 2003, a $26 \%$ decrease. According to the ASCP Board of Registry, of the 1,318 graduates who attempted the ASCP Medical Technician certification examination in 2002 for the first time, $74 \%$ were successful, reducing the numbers of employable graduate MLTs to 974 . These numbers were similar for 2003 , with a $75 \%$ pass rate for the first time attempt.

Over the past 10 years, approximately one third of clinical laboratory science programs have closed nationwide. In a survey of program directors in Medical Laboratory Science Programs conducted by the American Society for Clinical Pathology 
(ASCP) in 2007 "nine percent of the program directors that responded said there was a decrease in class size" (Bugbee, 2007, p. 468).

The State of Florida has 27 state-funded community colleges capable of housing MLT programs. According to the Florida Area Health Education Center (AHEC) of these 27 state-funded colleges only five are listed as having accredited MLT programs. Additionally, the program at St. Petersburgh College is now an on-line program that offers only didactic courses and faculty support to students completing clinical experiences. As a result, the number of community college programs in the state has been reduced to seven. This dramatic decrease in programs is of concern at a time when the U.S. Bureau of Census has projected an increase of $46 \%$ in Florida's population and a $128.5 \%$ increase in the elderly population (age 65 to 69 ) by the year 2020 (U.S. Census Bureau, 2005). (Hilborne, 2008), Furthermore, the employment outlook report from the Florida Area Health Education Centers (AHEC) indicates that, the number of Medical and Clinical Laboratory Technologists employed in 2006 was 8,559 . It is projected by 2014 there will be 10,170 , an annual average growth rate of 2.4 percent. The 2004 Bureau of Labor Statistics reports that 13,000 new laboratory professionals will be needed in the United States each year; however current training programs only graduate 5,000 students each year. (AHEC, 2009, p. 1)

The U. S. Department of Labor Bureau of Labor Statistics in their Occupational Outlook Handbook for 2008 has been projecting an increase of 43,000 MT and MLT positions by 2016. In their 2012 publication of the Occupational Outlook Handbook the Bureau of Labor Statistics reports that 
employment of medical laboratory technologists is expected to grow by 11 percent between 2010 and 2020, about as fast as the average for all occupations. Employment of medical laboratory technicians is expected to grow by 15 percent between 2010 and 2020, about as fast as the average for all occupations. An increase in the aging population will lead to a greater need to diagnose medical conditions, such as cancer or type 2 diabetes, through laboratory procedures (U. S. Bureau of Labor Statistics, 2012).

Therefore, given the current numbers of graduates and the projections for clinical laboratory professionals needed in the workforce, it is clear that clinical laboratory programs will not be able to offset the national need as projected by the Bureau of Labor Statistics.

The program shortage is compounded by pressure on existing faculty. Faculty members in MLT and MT programs face several challenges. First, they must continually work on the development of new and innovative teaching strategies that will assist students to be successful. Second, they must identify the academic characteristics that will allow students to progress through the program and reach graduation; finally, they must be mindful of the shortages in the field and maintain graduation rates that will address the ever-increasing demand for these professionals. For southeast Florida, it is evident that with graduation numbers ranging from 20 to 25 students per year, it is going to be difficult to meet the employment projections for clinical laboratories at hospital and reference laboratory facilities. Therefore, it will be necessary to identify predictors of success that can be used in the early detection of academic deficiencies. 


\section{Purpose of the Study}

This study intended to identify student factors that are associated with successful completion of MLT programs. The identification of these factors can assist faculty in advisement and possible remediation of at-risk students.

\section{Research Questions and Subquestions}

The study examined selected predictors of success in an A.S. degree Medical Laboratory Technology (MLT) program using a population of non-traditional students. The study examined the impact of the College Placement Test (CPT) scores, incoming student cumulative GPA (CGPA), science GPA (SGPA), and first semester in-program professional GPA (PGPA), on the prediction of retention and graduation rate for the Medical Laboratory Technology program. Demographic variables such as gender, ethnicity, and age were also examined.

Research Question: What student characteristics best predict successful completion of the Medical Laboratory Technology program?

Subquestions:

1. What academic preparation factors (College Placement Test, Cumulative GPA, Science GPA, and Professional GPA) are predictors of program completion?

2. Which demographic factors (gender, ethnic origin, and age) are predictors of program completion?

3. To what degree does performance on the CPT predict program completion? 
4. To what degree does GPA (Cumulative GPA, Science GPA, and Professional GPA) predict program completion?

\section{Significance of the Study}

The significance of this study lies in its impact on three general areas: (a) the individual MLT student, (b) the field of adult education, and (c) the Medical Laboratory profession. The individual MLT student has a desire to succeed and to complete the degree program in order to be eligible to sit for the certification examination and to gain employment in the profession. The exiting of students from the program before completion means that resources have been wasted and that dreams have been thwarted.

Clearly, the shortages of personnel and the program closures have placed new demands on medical laboratory technology programs to recruit more students and to develop strategies to decrease attrition and to increase graduation rates. Therefore, the ability to accurately predict student success and to implement strategies that will enhance student learning and decrease attrition will have a positive impact on graduation rates and the availability of trained professionals in the community.

There is a definite need for empirical research that will enhance the knowledge of adult educators in the health related fields of study, particularly in the field of Medical Laboratory Technology. While there is a wide body of research attempting to predict student success in nursing, little research was found in a review of the literature examining predictability of student success in Medical Laboratory Technology (MLT). Thus, predictive assessment that focuses on examining entry-level competencies of students will allow MLT educators to develop strategies for advisement and support that 
might mitigate the decreases in graduation rate, thereby increasing the numbers of graduates qualified to sit for national certification.

\section{Delimitations}

There are a number of issues that limit the general application of this study to different student populations and medical technology programs. First, although it would have been ideal to survey all MLT students across the U.S., this study investigated the predictors of success using a population of non-traditional students enrolled in a 2-year Associate in Science (A.S.) degree MLT program in South Florida only. Most of the students enrolled in the MLT program where the research was conducted are older commuter students who study part-time.

\section{Definitions of Terms}

The following are terms unique to this study that require specific definitions:

Academic Preparation Factors: Cumulative Grade Point Average (CGPA), Science Grade Point Average (SGPA), and Professional Grade Point Average (PGPA).

Academic success: Success in the MLT program and program completion within the prescribed two years and culminating in graduation within the prescribed 2 years from the Medical Technology Program.

American College Testing (ACT): An independent, not-for-profit organization that provides assessments, research, information, and program management solutions in education and workforce development. 
American Society for Clinical Pathology (ASCP): A national certification agency that administers a national examination with the goal of certifying competency of clinical laboratory professionals.

Clinical Laboratory Science (CLS): A global term that refers to the clinical laboratory profession and is sometimes used interchangeably with MLT. CLS is used by national credentialing agencies such as ASCP to refer to a 4-year educational program.

Clinical Laboratory Technology (CLT): A term sometimes used when referring to 2-year A.S. degree programs.

Computerized placement test (CPT): A test administered to students that assesses the student's skills in areas of math, reading and writing and is used to place students in either remedial or college level courses.

Cumulative grade point average (CGPA): Independent variable used in this study that will include all previous college work attempted by the student.

Medical Laboratory Technology (MLT): A global term that refers to the clinical laboratory profession. This term is used by national credentialing agencies such as ASCP to designate a 2-year A.S. degree program.

National Accrediting Agency for Clinical Laboratory Science (NAACLS): An agency that accredits educational programs in clinical laboratory science.

Professional Grade Point Average (PGPA): Independent variable used in this study that will include grades in the first semester of Medical Laboratory courses in the academic program. 
Science Grade Point Average (SGPA): Independent variable used in this study includes the grades in the pre-requisite science courses Anatomy \& Physiology, Chemistry, and Microbiology.

Standardized Admissions Test (SAT): Standardized test to determine if students are ready for college level work.

\section{Table 1}

Acronyms to be used in this Study

\begin{tabular}{ll}
\hline Acronym & \multicolumn{1}{c}{ Description } \\
\hline ASCP & American Society for Clinical Pathology \\
CGPA & Cumulative Grade Point Average \\
CPT & Computerized Placement Test \\
MLT & Medical Laboratory Technology \\
NAACLS & National Credentialing Agency for Clinical \\
CLS & Laboratory Sciences \\
SGPA & Clinical Laboratory Science \\
PGPA & Science Grade Point Average \\
CLT & Professional Grade Point Average \\
MT & Clinical Laboratory Technology \\
ACT & Medical Technology \\
& Standardized achievement examination \\
from ACT Inc. (originally American & College Testing) \\
SAT & SAT Reasoning Test (formerly Scholastic \\
& Aptitude Test and Scholastic Assessment \\
& Test) \\
\hline
\end{tabular}


Outline of the Dissertation

Chapter 2 includes a review of the relevant literature. This chapter encompasses the research related to healthcare educational programs and professions closely related to medical technology that are experiencing similar trends in recruitment of qualified candidates, attrition, and shortages of professionals in the field.

Chapter 3 examines the main research question and subquestions and includes a detailed analysis of the strategies used to answer each question. It presents the research design with the study methodology, rationale, the type of population and sample, instruments, procedures, and data analysis.

Chapter 4 presents the results of the study and a discussion of the findings for the main research question and subquestions.

Chapter 5 includes a summary of the findings with conclusions and recommendations. 


\section{CHAPTER II}

\section{REVIEW OF LITERATURE}

The purpose of this study is to identify student factors that are associated with successful completion of Medical Laboratory Technology (MLT) programs. Therefore, to achieve this goal, the study examined factors that contributed to attrition for students entering a 2-year institution in an MLT program. The goal of the study was to determine which student-level variables contributed to predicting graduation from the program. This chapter presents a review of the relevant literature, including research related to attrition.

\section{What is Attrition?}

At the core of the attrition process is the unplanned exit of college students that can either be academic or nonacademic in nature. However, despite the vast amount of research on this phenomenon, Tinto (1975) observed that there is much that is unknown regarding the nature of the process. In fact, it is this lack of knowledge that has led to contradictory findings stemming from efforts by researchers to aggregate behaviors leading to attrition into the global category of dropout.

Implicit in the definition of attrition is the fact that it is a gradual process and one that is defined by circumstances that affect the student within either the social or the academic sphere. Pascarella, Duby and Iverson (1983) explained that academic integration is determined primarily by the student's academic performance and his or her level of intellectual development. Social is primarily a function of the extent and quality of peer-group interactions and the extent and quality of student interactions with faculty. (p. 91) 
If attrition is caused by circumstances such as financial hardship (which includes personal economic hardship coupled with a lack of financial aid opportunities), family tragedy, increased level of family responsibility, work conflicts, or decreased level of support from family and friends, then it is in the personal social sphere. In fact, according to Tinto (1975), "very frequently, events in the social system external to the college can affect integration within the more limited social and academic systems of the college" ( $p$. 97). When attrition is due to institutional social isolation relative to poor personal connections to faculty and peers, then it is within the institutional social sphere. Finally, if the attrition is purely academic, it can be due to low grades, poor study habits, lack of academic support, or a poor academic foundation on which to build new knowledge. Clearly, each type of attrition is unique and is related to a different set of behaviors that require targeted strategies for their resolution. Thus, a careful study of the influences of attrition from 2-year institutions is not only prudent but also is necessary in the face of the current challenges facing higher education.

\section{Historical Overview Leading to the Development of the Theories of Attrition}

One of the first sociologists to examine attrition in higher education was Spady (1970), who is credited for developing a theory of student persistence and for incorporating within his theory Durkheim's ideas on suicide. In his work, Durkheim (as cited by Spady, 1970) theorized that the lack of social and normative integration of individuals into the fabric of society led to suicidal tendencies. Spady used Durkheim's ideas of detachment from society and suggested a parallel process was occurring in college students who dropped out from higher education. In his work, Spady theorized that college students who dropped out were in fact, severing their ties with the social 
sphere of the college much in the same way as individuals who commit suicide sever their ties to their local communities and society.

In 1975, Tinto built on the ideas of Spady (1970) and developed a theoretical model of attrition that is without question, one of the most researched and cited in relation to the study of persistence. Like Spady, Tinto agreed with Durkheim and felt that individuals who did not become socially integrated into the fabric of their community would ultimately withdraw. However, Tinto expanded his model by adding the influence of environmental variables adapted from Van Gennep's (1960) rites of passage theory.

In the rites of passage theory, Van Gennep (as cited by Tinto, 1975), emphasized the use of ceremonial rituals as essential components of a person's ability to integrate into a new environment. Van Gennep (as cited by Tinto, 1975) theorized that as a person moved from one place or phase to another, there were rituals or rites of passage that occurred which were marked by integration into the social fabric and served as evidence of success and acceptance. This anthropological base allowed Tinto's (1975) model to bridge the ideas of Van Gennep's rites of passage (as cited in Tinto, 1975) to higher education and to emphasize the student's ability to transition from high school to college, ultimately adjusting to the social and environmental setting of the institution. Thus, the ideas expressed in Van Gennep's rites of passage theory (as cited in Tinto, 1975) translated into Tinto's Student Integration Model in the form of a framework that included the concepts of separation from the family nucleus, transition from high school to college, and assimilation into the social sphere of the college.

According to Tinto (1975), dropout decisions occurred in the form of a longitudinal process that encompassed the interactions of the individual and the academic 
and social systems of the college. It is within the framework of these experiences that goals and institutional commitments are molded and lead to persistence or different types of dropout. Thus, Tinto indicated that "other things being equal, the higher the degree of integration of the individual into the college systems, the greater will be his commitment to the specific institution and to the goal of college completion" (p. 96).

In 1983 Pascarella et al. attempted to test Tinto's (1975) theoretical model in a nonresidential university setting to determine the explanatory power of the model in a commuter student environment. Additionally, they were also interested in testing the new construct of "intention" (intention to leave or stay) presented in the work of Bean (1981). Their findings suggested that aspects of Tinto's model can be applied to non-residential institutions particularly Tinto's concept of academic integration. Their observations indicated that:

Regardless of the type of post-secondary institution attended, it seems evident that persistence is predicated to a significant extent on the individual's attaining sufficient levels of structural integration (the extrinsic reward of grades), and normative integration (the intrinsic reward of intellectual development) in the institution's academic system. (p. 96)

In fact, Pascarella et al. (1983) determined other findings that were important in examining the applicability of Tinto's (1975) model in a commuter setting. Pascarella et al. (1983) revealed that precollege variables, such as sex and academic aptitude had significant direct effects on persistence. Additionally, Pascarella et al. reported that their results "tend to confirm expectations that, relative to the effects of the college environment, student pre-college characteristics may have a stronger direct influence on 
persistence in commuter institutions rather than in residential institutions" (p. 97). This aspect of the application of Tinto's model to commuter institutions gave credence to this study and highlighted the importance of examining precollege variables that are directly related to academic aptitude as one of the indicators of persistence.

In 1985 Bean and Metzner proposed a conceptual model of student attrition that considered the nontraditional student. According to Bean and Metzner, the nontraditional student is older than 24 years of age, does not live on campus (e.g., is a commuter), is enrolled part-time, does not need social affiliation (not influenced by the social environment of the institution), and is primarily interested in the institution's academic offerings that include courses, degrees, and certificates. For the purposes of Bean and Metzner's model, they also defined a dropout as a "student who enrolls at an institution one semester but does not enroll the next semester and has not completed his or her formally declared program of study" (p. 489). As in the case of previous researchers, Bean and Metzner felt that in spite of the fact that this unique student population had been previously included with traditional students in other models, there was little research devoted to examining the characteristics of this important segment of the student population. In fact, Bean and Metzner emphasized that, "No theoretical model has been available to guide attrition research on the nontraditional student enrolled in institutions of higher education" (p. 485).

Bean and Metzner (1985) pointed to the dramatic increases in nontraditional student enrollment that have been steered by institutional, curricular, social, political, and economic forces. In fact, of the 12 million college students enrolled at the time of their 
study, more than one half of the undergraduate students were women, two of five were over 25 years of age, and more than $40 \%$ attended part-time.

The Bean and Metzner (1985) conceptual model proposes four sets of variables (background, academic, environmental, and intent) with the assumption that students who exhibit poor academic performance will be more likely to dropout than students who exhibit good performance. In the model (See Figure 1: Conceptual Model of Nontraditional Student Attrition -Bean and Metzner 1985), Bean and Metzner included: background and defining variables, academic performance variables, environmental variables, and intent to leave. It is interesting to note that unlike previous models, environmental variables in the Bean and Metzner model were external and within the student's personal sphere rather than internal to the institution. Bean and Metzner stated that environmental "variables indicate those factors over which the institution has little control but which might pull the student from the institution” (p. 52).

Bean and Metzner's findings from their extensive review of the literature also showed that while the internal environment of the institution is extremely important for residential students, it is the external environment represented by finances, hours of employment, outside encouragement, family responsibilities, and opportunity to transfer that has the most dramatic effect for the nontraditional students.

In developing their framework, Bean and Metzner (1985) found that unlike residential students, nontraditional students interact with the institution through academic variables, therefore these variables were expected to have a direct effect on academic performance as expressed by GPA. This observation was not surprising since it was Spady (1970) who first pointed to the effect of college grades on the attrition process. 
Bean and Metzner (1985) also explained that since both Spady (1970) and Tinto (1975) developed their models using data on residential students, it is expected that (GPA) will have a direct effect on student attrition regardless of whether or not a student is traditional or nontraditional. Furthermore, it is important to note that the Bean and Metzner model of nontraditional student attrition went beyond Tinto's (1975) persistence theory to address some of its weaknesses and to test the importance of psychological and environmental variables as important factors in developing a model of student attrition.

In 1987, Tinto recognizing the mounting criticism regarding his theory, decided to revise his 1975 model and according to Metz (2000), acknowledged the need to expand the background variables and assess the role that academics and social integration played in the conceptual model of persistence. Metz recognized that the evolving process of student persistence needed the inclusion of Metz (2000) "psychological, societal, economic, organizational, and interaction factors" (p. 10). The addition of these new components were consistent with the findings of Bean and Metzner (1985) and with the findings of Cabrera, Cataneda, Nora, and Hengstler (1992), who indicated that "a major gap in Tinto's theory and allied research is the role of external factors in shaping perceptions, commitments, and preferences" (p. 144).

Figure 1 shows the Bean and Metzner (1985) Conceptual Model of Nontraditional Undergraduate Student Attrition. The research in this study addressed selected background defining variables and academic outcome (GPAs) in relation to possible prediction of timely program completion. Figure 2 shows the adaptation of the Bean and Metzner (1985) model that was used as this study's framework. 
In framing this study, the researcher used age, gender, and ethnicity (i.e., ethnic origin) variables found in the Bean and Metzner (1985) model as independent variables. College Placement Test math and reading scores were also independent variables used to represent the high school performance independent variable in the Bean and Metzner model. The variable academic outcome, which included GPA in the original model, was tested using independent variables (cumulative GPA, science GPA, and professional GPA). Finally, the dependent variable was timely completion or not completion. Figure 1 shows the Bean and Metzner (1985) Conceptual Model of Undergraduate Student Attrition. 


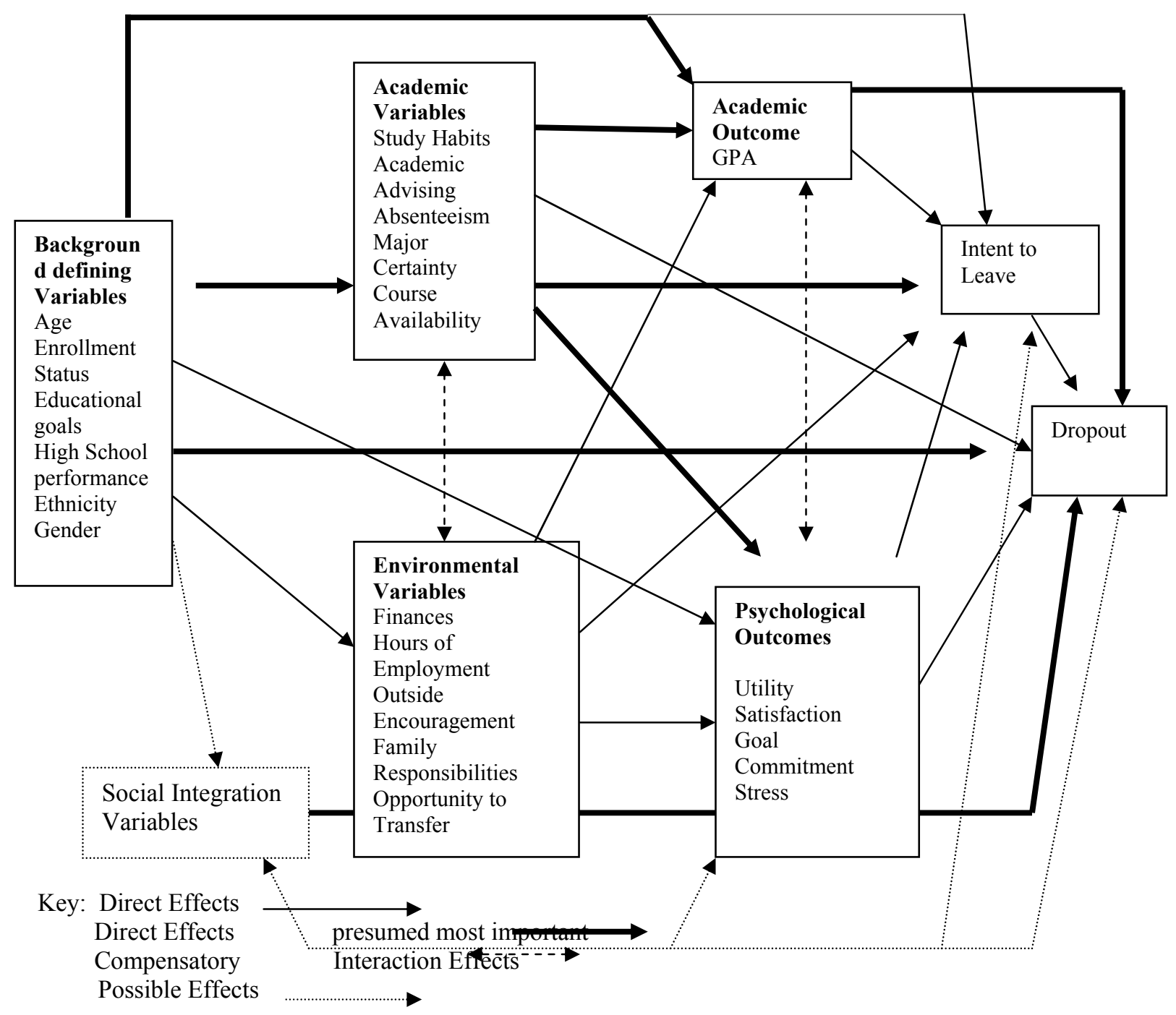

Figure 1. Bean and Metzner's Conceptual Model of Nontraditional Undergraduate Student Attrition.

From “A Conceptual Model of Nontraditional Undergraduate Student Attrition,” by J. P. Bean, and B. S. Metzner, 1985, Review of Educational Research, 55, p. 491. 
Figure 2 shows the framework used for this study modified from the Bean and Metzner (1985) model.

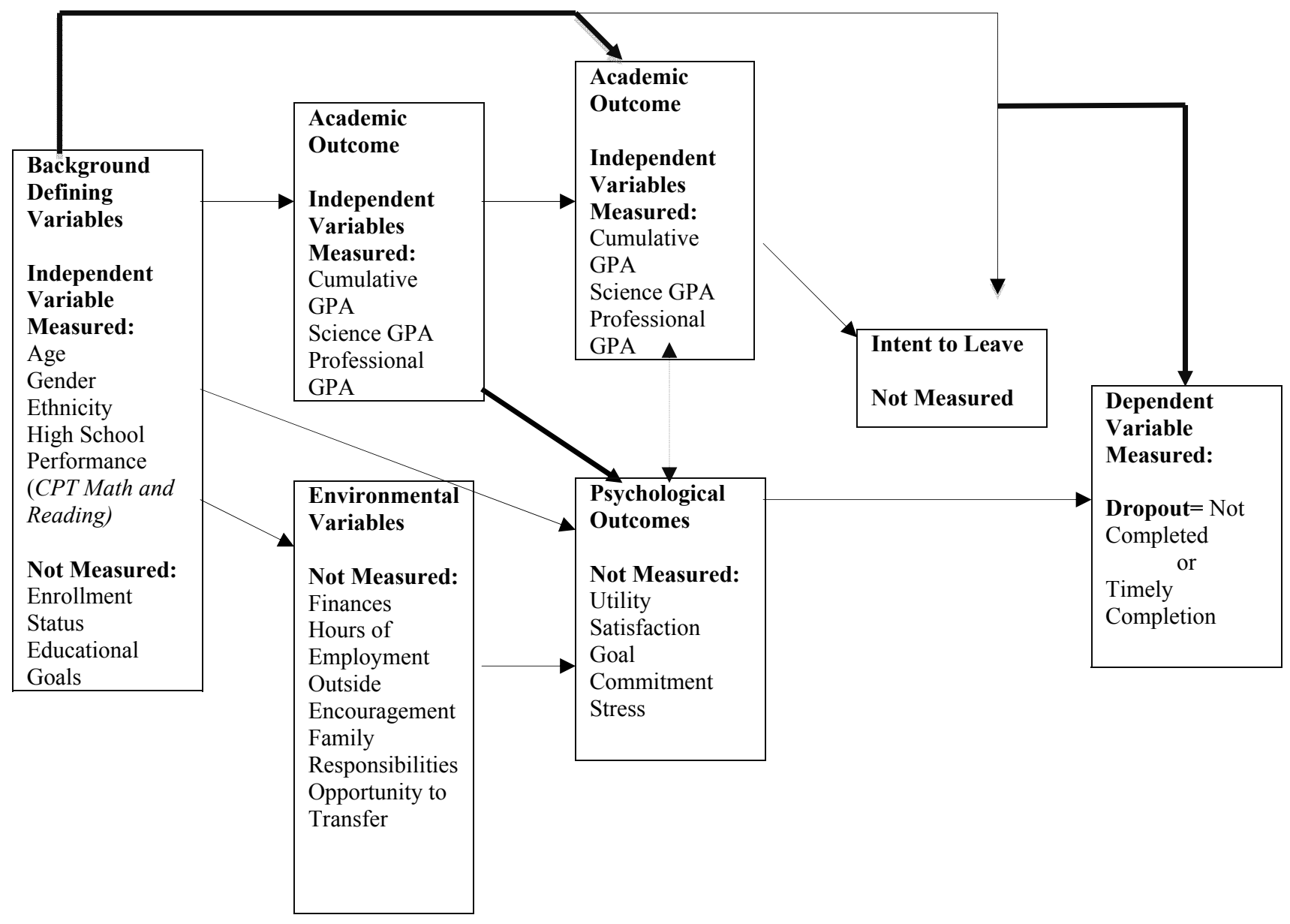

Key: Direct Effects

Direct Effects presumed most important

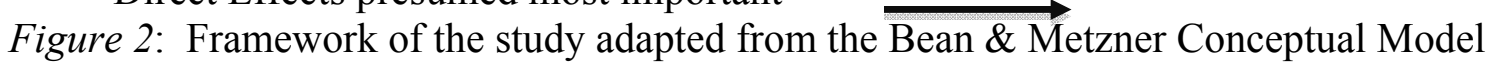
of Nontraditional Student Attrition. (Bean \& Metzner, 1985, p. 491).

During the 1990s, studies were being conducted that investigated the attrition phenomenon in 2-year institutions. Many of these studies were performed using data from community colleges. These institutions' efforts to increase retention were often tied to state funding. These studies, like others before, examined many of the same variables 
that had been used with studies in 4-year institutions. However, while many variables have been studied over the years, Summers (2003) emphasized the fact that academic factors have long been identified as predictors of attrition. In fact, according to Summers studies conducted at community colleges by Boughan (1998) and Lanni (1997) found that "students unprepared for college coursework were more likely to drop out" (p. 71). Lanni (1997), in his longitudinal study of student outcome, emphasized the importance of identifying at-risk students early in their careers so that intervention strategies could be initiated. In fact, Lanni stressed the importance of this type of intervention within the first semester. Notable about Lanni's study was his emphasis on the importance of math and English assessment as indicators of at-risk students. The recommendations of Lanni are important and further substantiate the need for this study from an academic perspective in examining the role that math and English proficiency, as expressed by the scores on the College Placement Test (CPT) has on persistence. Empirical Studies in the Health Sciences (Allied Health) and Nursing Programs

Although the shortage of licensed laboratory professionals has raised the bar for the success of in-program students, there have been few predictive studies of student success in medical laboratory technology, especially in 2-year A.S. degree programs. In fact, according to Kudlas (2006), "the use of the admission process to predict student retention has not been studied extensively" (p. 163). However, according to Goodyear and Lampe (2004), many other limited access programs like nursing, physicial therapy, and the like, face the same mounting challenges of identifying applicants who will be successful in completing their courses of study. In fact, Goodyear and Lampe indicated 
that while the ability to predict student success with $100 \%$ accuracy would be ideal, no single measure of success had been identified to date.

In researching the educational program literature in medical technology, there were few studies that addressed student success. Most of the studies identified, were conducted with 4-year baccalaureate hospital based programs (Downing, Mann, \& Tomlinson 1982; Elder, Nick, \& Fowler, 1997; Goodyear \& Lampe, 2004; Lanier \& Lambert 1981; Wiggers \& Holton, 2001) only one study, (Laudicina, 1999), was conducted in a 2-year community college program. These studies, while a valuable resource, primarily examined the effects of admission parameters on pass rates for the American Society for Clinical Pathology Board of Registry national certification examination. Thus, there is a need for more studies that look at what happens to those students who seem to fall through the cracks and never make it to graduation. Furthermore, given the present shortages of medical laboratory technologists, examining the student characteristics necessary for success becomes an important piece in addressing the attrition problem.

Despite this apparent gap in the medical technology literature, there are studies in other areas, such as nursing, that shed light on the problem of attrition. Examining studies with nursing students and other Allied Health professions is valuable because in all cases, there are similarities with respect to student academic characteristics necessary for success. Students in Allied Health and nursing programs need to be able to critically think through clinical situations to make decisions regarding patient care, this in addition to the similarities in the core prerequisite courses and the required level of proficiency in science, math and English. Given these important characteristics across health care 
professions and programs, examining the literature for nursing and programs in health sciences (allied health) can provide important clues into the characteristics necessary for success in medical laboratory technology.

\section{Medical Laboratory Technology}

The literature on medical laboratory technology, as it relates to academic programs, dates back to 1982 and an empirical study using a baccalaureate hospital-based program at Butterworth Hospital in Grand Rapids, Michigan. The study examined the students who were completing the program between 1970 and 1980. The program at Butterworth Hospital had a 35-year history, but was faced with asking the question, "does the applicant's college or university education make a difference in the ultimate success of the medical technology student?" (Downing, Mann \& Tomlinson,1982, p. 1005). In their study, Downing et al. analyzed data on the American Society for Clinical Pathology (ASCP) Board of Registry Examination score, year of graduation, sex, college preprofessional grade point average (equivalent to cumulative GPA), and length of program. The emphasis of the study was to find out if there were differences in the ASCP Board of Registry Examination scores that could be explained by differences in undergraduate school or length of program $3+1$ versus $4+1$. In a $3+1$ program, the student takes all the academic sciences, math and general education core in 3 years, then attends one year at a hospital-based program to do the theoretical and clinical portion of the program. A 4 +1 program, on the other hand, refers to a student who already has a B.S. degree in a chemical or a biological science and completes the professional portion in a 1-year hospital-based program. 
In addition to trying to determine if there were differences in scores between programs, Downing et al. were also interested in determining if there was an interaction between the undergraduate school attended and the length of the education program. This second piece of their research concentrated on examining the effect of sex and year of graduation on the ASCP Board of Registry score as well as the differences in college GPA by sex, school, and year of graduation. The results of this study revealed "a moderately positive relationship between college grades and ASCP Registry scores. However GPA accounted for only approximately $14 \%$ of the variance of Board of Registry examination scores" (Downing et al., 1982 p. 1008). While this retrospective study was significant as an early assessment of Board of Registry scores and possible predictors of success, the authors cautioned regarding the use of the results in generalizing to other settings and populations.

Another notable research study was performed by Goodyear and Lampe (2004), who explained that at the University of Washington Medical Technology Program (UWMTP), the program uses five items for ranking their applicants in the admission process (cumulative GPA, science GPA, letters of recommendation, a personal interview, and the score on the AHPAT). It is important to note that Goodyear and Lampe's study examined not only the total score on the AHPAT but also the score on the biology and verbal subsections. According to Goodyear and Lampe, "When AHPAT subsections were evaluated on the basis of program outcome, the biology subsection was the most significant, with a $2.8 \%$ decrease in the risk of failure for each unit of increase in score" (p. 22). This is important because while this study did not examine specific Allied Health 
standardized test scores, it did examine the role science GPA plays in student success. In fact, Goodyear and Lampe (2004) stressed

The biology subsection was the only one that retained significance for program outcome, perhaps indicating the necessity for a solid understanding of biology as the foundation for the scientific body of knowledge that we teach. We also found that the verbal subsection was the only significant predictor of success in the BOR (Board of Registry), perhaps indicating the greater influence of English language skills in a testing format with no laboratory component. (p. 23) While the correlations of cumulative GPA (Cum GPA) and science GPA (Sci GPA) were not as impressive in the Goodyear and Lampe study when compared to those between success and the AHPAT, there was a higher correlation between Sci GPA and Medical Technology Program GPA (MTP GPA) than between Cum GPA and MTP (GPA), indicating the possible importance of a strong science background to success in a medical technology program.

Two studies conducted with medical technology students were identified between 1999 and 2001. The first study, Laudicina (1999), examined academic and environmental characteristics of clinical laboratory technician students and their effect on program outcome. The second by Wiggers and Holton, 2001, examined the predictive value of a departmental senior comprehensive examination as a predictor of performance on the BOR national certification examination. The Laudicina study was significant because it examined a different A.S. medical technology degree program. To conduct the study, the researcher developed a survey instrument that was pilot-tested prior to use to determine the factors that characterized clinical laboratory technician (CLT) student attrition. 
Laudicina asserted that "because most attrition research on the general college population has been conducted on traditional college students attending four year residential institutions, a different approach that takes into consideration the differences between traditional and nontraditional college students is needed" (p. 222). Laudicina posited that Tinto's (1975) theory of attrition was not applicable to nontraditional college students because these students were commuters and did not have the same social integration that traditional students have. Instead, Laudicina pointed to another model of attrition proposed by Bean and Metzner (1985). Using the Bean and Metzner model, Laudicina proposed to answer the following questions: What is the frequency of attrition in CLT programs? Is academic dismissal a more common reason for attrition than voluntary dismissal? Are there differences between graduates, voluntary withdrawals, and academic dismissals on the basis of background and demographic characteristics, academic variables, and environmental factors? (p. 223)

Laudicina (1999) used 1,527 complete data sets, including program outcome. Significant differences were found among 8 of the 16 variables analyzed: age, importance of college degree, current GPA, study time, certainty of major, support of faculty, hours of employment, support from friends. Laudicina was examining not only academic variables expressed through GPA but also environmental and demographic variables. One of the findings in the Laudicina study was that "almost $25 \%$ of the 1,577 medical technology students in the study did not persist to graduation" (p. 224).

Several pieces of this study identified areas that played a significant role in student attrition. For example, Laudicina found that medical technology graduates were more than 2 years older than students who were academically dismissed. This is 
consistent with previous studies of maturity and judgment found in the literature for other groups such as nursing. The study also found that graduates rated the importance of a college degree higher than students who voluntarily withdrew. This is consistent with numerous studies on the general college population and the relationship of commitment to educational goal and persistence. Laudicina believed that "lacking a strong commitment to earning a degree, some students may find the demands of the Clinical Laboratory Technology (CLT) program or their personal lives excessive, and voluntarily withdraw" (p. 224).

Laudicina (1999) found the following relating to the area of GPAs:

All outcome groups differed significantly on GPA, with graduates reporting the highest GPA followed by voluntary withdrawals and academic dismissals, respectively. That GPAs of voluntary withdrawals were lower than were those of graduates leads one to question the academic performance of voluntary withdrawals....Graduates also reported spending significantly more hours each week studying than voluntary withdrawals, but there was no difference in study time between graduates and academic dissmisals. (p. 225)

Thus Laudicina postulated, "Possibly students who ultimately fail suffer from qualitative rather than quantitative deficiencies in study habits" (p. 225).

Environmental factors also played a significant role. For example, graduates were found to work fewer hours per week and had a more supportive circle of family and friends than voluntary withdrawals. Additionally, all groups (graduates, voluntary withdrawals, and academic withdrawals) were found to spend fewer hours engaged in social activities, which may reflect that clinical laboratory technology (medical 
technology) programs require demanding academic schedules. Finally, it was found that "all outcome groups reported moderate levels of conflict between roles as students and personal lives and moderately high levels of family support and financial concerns" (Laudicina, 1999, p. 225).

While the Laudicina 1999 study examined some of the qualitative factors that affect student success, it is significant to this researcher's study in its findings regarding GPA and its relationship to voluntary withdrawals from the program. Furthermore, this relationship brings to the forefront the need to identify and address academic deficiencies early so that program retention and graduation rates can be improved. Another important point regarding the Laudicina, 1999 study was that she characteristics the study population as one which "very much fits the definition of 'nontraditional', as the average age was 27.8 years and most were enrolled at community colleges which are primarily commuter schools" (p. 224). This is an important point because the student population in this study was 25 years of age and commuter attending a community college. Nursing

The examination of studies relating to nursing was important for two reasons. First, there are similarities between pre-nursing and pre-medical laboratory technology students that relate to student populations, such as demographics, socioeconomic status, and prior-pre-requisite coursework. Second, there is an extensive body of knowledge that relates to predictors of academic success using nursing students. Thus, because of the similarities in the students and the curriculum, it was important to look at the research within the nursing profession. 
Researchers Wong and Wong (1999) examined the contribution of basic sciences to student success in the nursing program and on the Canadian Nursing Association Testing Service (CNATS) examination. The researchers conducted their study in a 4-year nursing program in Canada. Their goal was to make the case that the contemporary health environment in which nurses practice requires that nurses possess a more diverse knowledge base that is supported not only behavioral but also by physical and biological sciences (Introductory Physiology, Anatomy, Microbiology, and Chemsitry). The outcome variables examined were cumulative grade point average (CGPA) and the CNATS examination score with CGPA used as a measure of academic success and the CNATS score as a measure of professional success.

A review of the relevant literature uncovered evidence that outcome variables such as CGPA and success in the biological and physical sciences as well as nursing courses were significant predictors of success and could explain as much as $34 \%$ of the variance in the licensure examination. According to Wong and Wong (1999), "The majority of published studies indicate that basic sciences are significant predictors of student success within the nursing curriculum" (p. 346). In fact, Wong and Wong asserted that the impact of basic sciences on program and licensure examination success has been inadequately explored.

An examination of CGPA and Science GPA (Sci GPA) by Wong and Wong (1999) revealed a significant correlation between the two variables. Additionally, while age seemed to exert the greatest magnitude of influence on academic success, it was closely followed by success in chemistry. In fact, the model showed that Sci_GPA was a significant predictor of student success in the program and had the largest effect on 
student academic success. According to Wong and Wong, "It was noted that science GPA and the GPA of the third year nursing courses could account for $56 \%$ and $50 \%$ of the variance in success within the program, respectively" (p. 349).

Wong and Wong also used logistic regression to examine the probability of failure for the nursing program using CGPA as an indicator of academic success. Variables included in the model were basic science GPA, GPA of the first-and second year nursing courses, and age at the time of program entry. Their findings showed that all four predictors were significant in predicting the likelihood of unsuccessful program completion. In fact, according to Wong and Wong, (1999) "the risk of failure was nearly half as great among students with a low GPA in the first year nursing courses in comparison with those whose first year nursing GPA was high" (p. 351).

The implications of the Wong and Wong study with a nursing program clearly support the study of the contribution the basic sciences can make to the success of students in a medical technology program. While the influence of a strong basic science foundation on nursing is significant from a review of the Wong and Wong study, the influence on medical laboratory technology has not been studied. A common denominator between nursing and medical laboratory technology is the importance of the ability of students to learn to think critically and logically. In both cases critical and logical thinking is a component to safe and competent practice. Therefore, just like in nursing, students in Medical Technology must possess the analytical and problem-solving skills necessary to be successful in their program coursework and, ultimately, make the appropriate decisions for patient care. Thus, this study showed that for the nursing 
student, knowledge of the basic sciences is essential to the understanding of pathology, physiology, and the complex processes of patient care. In the same manner, this research study examined the contribution that basic sciences in the form of Science GPA (SGPA) makes on program success.

Another study with nursing students in a baccalaureate program in the United Kingdom examined predictors of academic success. The researchers, Wharrad, Chapple, and Price (2003) also concluded that an examination of the amount and the quality of the biological sciences that program candidates have studied should be considered as a piece in the selection criteria puzzle.

Daley, Kirkpatrick, Frazier, Chung, and Moser (2003) investigated demographic and nursing program variables in a baccalaureate program to determine if there were differences between students who were successful on the National Council Licensure Examination for Registered Nurses (NCLEX-RN) and those who were not successful. Their findings confirmed the findings from the nursing literature. According to Daley et al. (2003), "several program predictors (i.e., final grades for anatomy, pathophysiology, and the didactic and clinical medical-surgical nursing course; cumulative GPA) were found to be significantly different in students who were successful on the NCLEX-RN and those who were not" (p. 396). This observation by Daley et al. again supported the importance of science grades and cumulative GPA in predicting success on the NCLEXRN. It is important to note that while the Daley et al. study did not look at these predictors with relation to program success, students must be successful in their program coursework to graduate and to qualify for the national licensing examination in nursing. 
Examining the entry, progression, graduation, and licensure of nursing students was the focus of a study by Jeffreys (2007). Jeffreys' study was conducted with associate degree nursing students with the goal of "exploring various nursing student progress trajectories, developing composites of successful student, and developing composites of the at-risk student" (p. 408). In fact, Jeffreys emphasized the need for more studies with discipline-specific programs and non-traditional students to examine program completion, stopouts, and educational outcomes.

Several progression/retention trajectories were examined in the Jeffreys study. Statistical data analysis suggested that empirically, there needs to be an emphasis "to provide a strong foundation, identify at-risk students early, and develop early intervention to enhance success" (Jeffreys, 2007, p. 416). In fact, Jeffreys found a strong academic correlation between first-time success on the RN licensing examination and a "B" or higher nursing course grade average (NCGA). Jeffreys indicated that " $100 \%$ of students who achieved a "B" NCGA passed the licensure on the first attempt" (p. 417). This was significant for this research, which looked at first-semester program grade point averages and the link to success in the medical laboratory program. It is important to note the similarities between the student progression through the nursing and the medical laboratory technology curriculum. Students in both programs must progress through the courses and clinical experiences to graduate before they can attempt to sit for certification or licensure, as in the case of nursing, at the national level.

Another significant study using the nursing student population in a baccalaureate program was conducted by Potolsky, Cohen, \& Saylor (2003). Their study examined the association between prerequisite science course grades and academic performance of 
nursing students in their first semester. According to Potolsky et al., "the study hypothesized that student's academic performance in prerequisite science courses would correlate positively with their academic performance in first semester nursing courses" (p. 247). Findings from the study were consistent with previous studies and demonstrated a high positive correlation between average prerequisite course grades and success in nursing courses. High positive correlations were associated with pathophysiology grades, while moderate positive correlations were observed with pharmacology grades. Thus, Potolosky et al. asserted, "the results of this study support the hypothesis that prerequisite course grades have a relationship to the academic performance of first semester nursing students. The analysis of the association between prerequisite course grades and firstsemester performance are statistically significant” (p. 249).

More recently, Hopkins (2008) studied first-semester nursing students in an associate degree in nursing (ADN) program to develop a prescription for the early identification of at-risk students. According to Hopkins, "identifying factors that predict student success and applying student support interventions early in the first semester can affect student persistence" (p. 254). Hopkins explained that the goal of the study was to examine the extent to which academic and nonacademic variables illustrate success in the first semester as defined by achieving a passing grade of $80 \%$ on the Nursing Fundamentals course.

The Hopkins' study examined both academic and nonacademic variables, such as cumulative high school GPA, cumulative college GPA, and math and reading composite scores on the Nursing Entrance Test (NET). Nonacademic variables included demographic data such as age, gender, and race. The researchers were successful in 
developing a model that predicted those students who would be successful. According to Hopkins, "predicted success was good, with $99 \%$ of the successful students correctly identified and an overall success rate of $82.5 \%$ " (p. 258). While the ability of the model to predict unsuccessful students was not as good, $5.9 \%$, it is important to note that any efforts that bring us closer to predicting success is a valuable endeavor.

There are a plethora of studies in the nursing profession examining predictors of success as they relate to pass rates on the NCLEX examination. Many of those studies focused on predicting academic success at university-level baccalaureate programs. A study conducted by Lewis and Lewis (2000) aimed to identify students at-risk at the time of transfer by examining factors related to success and failure in a transfer student population. This study was a change from the traditional studies in the literature, which focused on demonstrating outcomes of nursing educational programs using pass/fail on the NCLEX-RN as a measure of success. In fact, the study was a shift in the focus from success on the NCLEX-RN to characteristics of student success. This shift in focus was important given the numerous calls in the literature for individual nursing programs to identify their at-risk student populations.

The Lewis and Lewis (2000) study examined three years of data between 1991 and 1994, and looked at specific coursework, such as numbers of transferred social science, natural science, and physical science courses, total number of transferred credits, incoming GPA, and type of institution from which the student was transferring 4 year or 2 year institution. Lewis and Lewis (2000) determined that:

there was a difference between successful students and unsuccessful students in the number of anatomy/physiology courses taken. Successful students 
typically had taken two or more anatomy/physiology courses prior to admission. In contrast, unsuccessful students, on average, had taken one anatomy/physiology course at most. Another important finding of this study was related to the prediction of final college GPA. (Findings section, p. 1)

Additionally, Lewis and Lewis found two areas that were mildly predictive of identifying at-risk students. One was the type of transferring institution and the number of anatomy/physiology courses taken prior to admission.

Lewis and Lewis (2000) emphasized that "the importance of anatomy and physiology is not surprising because these two areas are fundamental in distinguishing normal from abnormal when assessing human responses, and they are the foundation for understanding human pathophysiology" (p. 1). In fact, the researchers found that incoming nursing applicants who had taken the required number of anatomy/physiology courses were more successful in their nursing coursework. These are important findings and further evidence that examining prerequisite science coursework in the applicant population is an important variable and one that needs to be examined with the incoming population of medical technology students. Furthermore, the similarities between the required academic abilities between nursing and medical technology students in distinguishing normal from abnormal warranted a study of the medical technology students and the predictive value of Science GPA (SGPA) in their ability to graduate from a program of study.

There have also been significant studies examining other populations of nursing students. A study by Stickney (2008) examined attrition in a community college practical nursing program. Practical nursing programs are characteristically one-year vocational 
certificate programs that prepare students to work under the supervision of a licensed registered nurse or a physician. According to Stickney, "Licensed practical nurses [Practical Registered Nurses PRN], who usually are not included in the predictions or strategies to address the [nursing] shortage, could contribute to easing of the shortage among employers in the process of reconfiguring the institutional environment toward a team approach" (p. 422).

There were several academic variables studied by Stickney (2008) among them were the student's previous level of education, grade point average (GPA), admission test scores, and the method of high school completion (Stickney, 2008). Demographic data were also collected and included age, race, and gender. This retrospective study used data obtained from school records over a 3-year period. It is important to note that admission test scores used in Stickney's study as part of the academic variables "included total scores and subscores on the Test of Adult Basic Education (TABE), which is used as a preadmission screening tool...to determine academic readiness for all vocational programs" (p. 423). Furthermore, the College Placement Test (CPT) that was examined in this study is used as a preadmission screening tool for students registering for college credit courses that were pre-requisites for the medical technology program. Both the TABE and the CPT assess math, verbal/language, and reading ability. Also of importance is the fact that approximately half of the students were from minority populations with an average age of 34 years. To assess the causes of attrition, the Stickney study also collected additional academic data. Grades earned in two of the prerequisite courses, Introduction to Health Care and Medical Terminology, were also examined. The results of the study revealed an overall attrition rate of $36.6 \%$ for all participants consistent with 
previous studies on this type of student population (Stickney, 2008). Additionally, Stickney (2008) indicated that

academic variables as measured with the TABE test and prerequisite courses, were significantly different for students in the retention group compared with students in the attrition group. Students in the retention group had overall higher academic ability than did those in the attrition group (p. 424).

Other variables such as age, gender and race revealed that while age and gender did not yield a statistically significant difference between the groups, race was the only statistically significant variable in the attrition rate calculation. Thus, pointing to the importance of social integration within this group and the recommendation of Stickney (2008), that this important variable to the attrition equation be addressed with "study and support groups, referral to student services, and frequent contact with advisors in the nursing program" (p.424).

\section{Health Sciences}

Studies in other areas of the health sciences have examined predictors of success. A study by Downey, Collins, and Browning (2002) was conducted to examine the predictors of success in dental hygiene education. This was a 6-year review looking at the predictive value of incoming GPA, incoming math/science GPA, and the score on the Scholastic Aptitude Test (SAT) in predicting success of students in dental hygiene education. In the study, success in dental hygiene education was defined as success on passing the Dental Hygiene National Board examination and the graduate dental hygiene GPA. Downey et al. (2002) indicated that survey information "reveal that the majority of 
dental hygiene programs consider overall college GPA and college science GPA in their admission process" (p. 1269).

Downey et al.'s (2002) study used multiple linear regression to analyze the data, which included incoming GPA (I-GPA), math/science GPA (MS-GPA), SAT total score, SAT verbal score, and SAT math score. Findings of the study showed that knowing the incoming GPA (non-math/science) in addition to the math/science GPA significantly increased the ability to predict DH-GPA. Furthermore, knowledge of the I-GPA and MSGPA also significantly increased the ability to predict performance on the Dental Hygiene National Board Examination. Thus, in this study, knowledge of the SAT total score, verbal score, and math score did not add to the prediction of student success in dental hygiene. Downey et al. suggested hat while standardized tests have been useful in predicting student academic success, there are concerns regarding the validity of these scores in predicting academic success within minority populations. In fact, Downey, et al. pointed to surveys of allied health programs that have shown that standardized test scores were rarely used in student selection.

In 2004, Bauchmoyer, Carr, Clutter, and Hoberty examined academic factors that could predict academic and National Board Dental Hygiene Examination (NBDHE) success. Bauchmoyer et al. began by pointing to the existing literature in health programs by reaffirming that "students who are better academically prepared will perform better in health-related programs and are more likely to pass credentialing exams" (p. 39). The authors listed the many variables that have been studied with relation to Dental Hygiene. These variables encompassed ACT and SAT scores, demographics, high school GPA, high school science GPA, Dental Hygiene Aptitude test scores, college 
science GPA, mock examinations, and college grades in courses such as anatomy, sociology, nutrition, and psychology.

The purpose of Bauchmoyer et al.'s (2004) current study was to determine the viability of existing predictors of success for the Dental Hygiene program and the NBDHE at Ohio State University. While numerous studies have explored predictors of student success in dental hygiene programs and on the NBDHE, there were no studies that examined the existing predictors since the 1998 changes to the NBDHE. Thus, the objective of their study was to assess "the relationship between pre-admission requirements, basic college science requirements, site of academic preparation, cumulative dental hygiene grade point average (CDHYGPA) and the NBDHE score" (p. 39).

A 6-year review of the predictors of success was studied by Downey, Collins, and Browning, (2002) to determine the reliability of incoming GPA, math and science GPA, and SAT scores in determining the success of students in Dental Hygiene education. Surveys of Allied Dental Education conducted by the American Dental Association between 1996 and 2000 indicated that Downey et al. (2002) Dental Hygiene programs use the following criteria for student selection:

high school grades (science grade point average [GPA], non-science GPA, overall GPA, and other), college grades (science GPA, non-science GPA, overall GPA and other), test scores (ACT, SAT, and other), manual dexterity exam, preadmission interview, letters of recommendation, and dental office experience. (p. 1260) 
Of the above-mentioned criteria, the Downey et al. (2002) study determined that the majority of Dental Hygiene programs use overall college GPA and science GPA as part of their selection criteria.

Although previous research has established that standardized test scores are significant predictors of academic success, there is controversy regarding their use in the prediction of success within minority student populations. In fact, Scott et al. (as cited in Downey et al. (2002) reported on a 1995 survey which found that, "standardized tests were rarely used in the selection process for allied health students" (p. 1269).

In their study, Downey et al. (2002) were interested in examining the "predictive reliability of admissions data in predicting student success in dental hygiene education" (p. 1270). In Downey et al.'s study, dental hygiene education was defined by two variables: "Dental Hygiene National Board score (N-BRD) and dental hygiene grade point average at graduation (DH-GPA)" (p. 1270). Cognitive criteria variables were also identified as potential predictors of success: incoming college GPA (I-GPA), incoming math/science GPA (MS-GPA), total SAT score (T-SAT), verbal SAT (V-SAT), and math SAT (M-SAT). Demographic data such as gender, ethnicity, and age were also examined for each student. A multiple linear regression model was used to analyze the data and the findings supported the following observation: Knowledge of non-math/science GPA, math/science GPA, V-SAT, and M-SAT added significantly to the prediction of Dental Hygiene GPA. Additionally, non-math/science GPA, and math/science GPA added significantly to the ability to predict performance on the Dental Hygiene National Board Examination (Downing et al.). 
While the results of the Downing et al. study found that V-SAT when used independently did demonstrate a significant correlation with the Dental Hygiene National Board scores, the researchers indicated that the most efficient model for prediction did not include the V-SAT. In fact, knowledge of the V-SAT, M-SAT, or T-SAT did not add significantly to the ability to predict success on the Dental Hygiene National Examination. However, the I-GPA proved to be a better predictor (Downing et al. 2002).

Clearly, the findings of the Downing et al. study again suggested the importance of incoming GPA and science GPA as possible predictors of success in Allied Health. Furthermore, Downing et al indicated that the data in their study supported the use of incoming GPA and total SAT as part of the selection criteria for their institution's dental hygiene program.

A study by Op’t Holt and Dunlevy (as cited by Bauchmoyer et al., 2004) examined predictors of success in a respiratory therapy program. In that study, Op't Holt and Dunlevy as cited in (Bauchmoyer et al., 2004) "found a positive correlation between pre-professional GPA, science-math GPA... and the [respiratory] program completion GPA at The Ohio State University" (p. 41). The results of the Op't Holt and Dunlevy as cited in (Bauchmoyer et al., 2004) study concluded that prerequisite courses which include biology, two semesters of chemistry, English, math, introductory psychology, and math or logical analysis were all important in prediction of success as measured by CDHYGPA. In fact, the cumulative GPA of all prerequisites was the best predictor. Op't Holt and Dunlevy as cited in (Bauchmoyer et al., 2004) indicated that, "the strongest predictor in a single course within the prerequisites was biology" (p. 43). In fact, the Op't Holt and Dunlevy study (as cited in Bauchmoyer et al., 2004) reported similar findings in 
their assessment of predictors of success in a respiratory therapy program where they found "math-science GPA and pre-professional GPA as accounting for the greatest variance in cumulative GPA" Op't Holt and Dunlevy (as cited in Bauchmoyer et al., 2004) (p. 43).

Human nutrition, one of the core science courses typically completed after matriculation to the dental hygiene program was found to be the strongest predictor of CDHYGPA. The findings in the Op't Holt and Dunlevy (as cited by Bauchmoyer et al., 2004) confirmed findings in previous studies for other health sciences such as nursing. The importance of the study was the fact that there had been no studies to examine the validity of existing predictors of success in Dental Hygiene since the 1998 changes to the NBDHE. Moreover, this study was important because it supported the researcher's study which looked at science GPA (SGPA) as a predictor of success in medical laboratory technology. Other findings examined by Op’t Holt and Dunlevy (as cited by Bauchmoyer et al., 2004) were the possible effects of academic preparation at a community college versus a 4-year institution on cumulative dental hygiene grade point average where the study found no statistical difference between the site of academic preparation and CDHYGPA Op’t Holt and Dunlevy (as cited by Bauchmoyer et al., 2004).

Many other allied health programs have examined their admission practices and looked at predictors of success or retention for their programs. Kudlas (2006) examined the admission practices of 2-year radiography programs to determine the extent of their effect on retention rates. Because Allied Health programs have selective admission Kudlas made an important point by stating that attrition, regardless of how small, has negative effects for the profession since a student who leaves the program creates a void 
that cannot be filled until the program completes the admission cycle, sometimes as much as a year later. Thus, the focus of the study was to not only look at retention rates but also to examine whether retention and admission practices were different between programs that use competitive admission versus those that did not. Independent variables for the study were high school GPA, college GPA, selective GPA, reference checks, writing sample or goal statement, reference letters, drug testing, background checks, personal interview, and departmental observation. The study included the responses of 327 programs and the dependent variable was the retention rate for each program. Results of the study regarding the effect exerted on retention from using specific admission criteria showed that "the use of reference letters and selective GPA were the only two factors that correlated with significantly increased retention rates among programs that use competitive admission practices" (Kudlas, 2006, p. 167).

Pharmacy programs have also studied predictors of academic success. A study done at Texas Tech University School of Pharmacy examined precollege variables and academic success in the doctor of pharmacy program. The aim of the study was to "explore the association between advanced chemistry, biology, and math coursework (junior and senior level college classes beyond required prerequisites) as well as attainment of a prior college degree (BS, BA, and MS) with academic success in pharmacy school" (McCall, Allen, Fike 2006, p. 2). Findings of the study revealed that of all the indicators, pre-pharmacy GPA, completion of advanced courses in biology, and earning a BS degree were significantly associated with a higher GPA in the first professional year (P1 GPA) in pharmacy school. Among the variables not significantly correlated with GPA were taking advanced math, chemistry, or organic chemistry in a 2- 
or 4-year institution and having a BA or MS degree prior to admission. Pursuant to McCall et al., "completing advanced prepharmacy biology coursework, was significantly associated with a higher likelihood of graduating on time and avoiding academic delay or suspension...." (p. 3). "Furthermore, having taken advanced biology courses prior to starting pharmacy school and earning a BS degree were significantly associated with a higher mean cumulative GPA" (McCall et al. p. 3). In fact, McCall et al. (2006) stressed that advanced biology coursework was significantly associated with a higher P1 GPA among all students admitted, a higher cumulative GPA among graduates, and graduation without academic delay or suspension "[with an] observed absolute difference of $8.6 \%$ in the rate of academic delay or suspension among the students" (McCall et al. p. 5).

This observation was important because although this research looked at advanced coursework in biology and its application to retention and GPA, it highlighted the importance of the biological sciences as part of the foundation for study in the health professions. Examining science GPA, which included courses in Anatomy and Physiology in the entering class for the medical laboratory technology program, provided a starting point for assessing the role of science prerequisites in student success.

\section{Medical Education}

A review of the literature on medical education in the United Kingdom was completed by Ferguson, James, and Madeley (2002) to examine the selection of students to medical schools in the UK. According to Ferguson et al. selection practices have recently been scrutinized due to the observations of other researchers who have identified biases toward White applicants in the selection process. In fact, problems with biases have become high-profile cases in the UK and have prompted questions from the public 
regarding admission practices in medical schools. The focus on the problem prompted The Committee of Deans and Heads of Medical Schools to commission a study of significant predictors of success in medicine. The study examined the existing literature looking for studies that looked at predictors of success for both undergraduate and postgraduate medical education. Their findings were consistent with the reviews found for other occupational areas and cited academic or cognitive ability as a moderate predictor of academic success in undergraduate medical education (Ferguson et al., 2002).

\section{Summary}

It is clear that a review of the vast literature related to attrition points to the importance of academic, social, and environmental factors in examining the dropout phenomenon. Additionally, it is also clear from the literature review that there is great congruency between the work done by researchers in nursing, health sciences, and medical education and this researcher's study. Many of the variables (CGPA, SGPA, and PGPA) that were examined in this study, have been examined with other populations of students and within other disciplines in the healthcare field. Other variables such as demographic factors can be traced to empirical studies performed by Tinto (1975), Bean and Metzner (1985), and others.

While some studies in this literature review have examined SAT scores, no study has looked at what contribution, if any, CPT scores makes in predicting program completion. 


\section{CHAPTER III}

\section{METHODS}

The purpose of this study was to examine the problem of attrition in a 2-year A.S. degree medical laboratory technology program. This ex post facto study examined the relationship between selected student characteristics identified in the literature and student success in the medical laboratory program as measured by program completion. All data collection was accomplished at the campus using the Student Tracking and Odyssey systems. The Odyssey system is an integrated online database that is used internally in the day-to-day operations of the college. Information such as cumulative GPA, science GPA, demographics, and College Placement Test (CPT) math and reading scores were obtained from the Odyssey Student Information System and Student Tracking. First-semester GPA or Professional GPA that included only the first semester of program medical laboratory courses was calculated from the grades obtained from the degree audit using Odyssey’s Student Information System.

This retrospective study used a logistic regression analysis model. The purpose for selecting such a design is to determine the relationship among the variables and the contribution of each of the predictor variables to the criterion variable, completion. In this study, completion was defined as completing the academic program in the prescribed 2 years. Two years was used as the dependent variable because besides being the prescribed time of completion for the program, this time frame is consistent with the nature of 2-year, Associate Science degree programs. The logistic regression analysis was used to examine the student-level variables and their contribution in predicting the dependent variable, completion. The independent variables used were the College 
Placement Test math and reading scores which are used to determine whether a student was placed in remedial courses or was academically qualified to take college-level courses in English and math, cumulative GPA (CGPA), science GPA (SGPA), firstsemester professional GPA (PGPA), and demographic variables (gender, age, and ethnicity).

\section{Sample}

Participants for this study were drawn from the students admitted to the Medical Laboratory Technology program at a medical campus in an urban 2-year college in South Florida between 2000 and 2010. Because incoming classes typically tend to have 15 to 20 students, this study included student records within a ten-year time frame. The examination of records that dated back to 2000 produced 158 student files. Tabachnick and Fidell (2001) noted that there are a number of factors that influence the required sample size. However, Tabachnick and Fidell suggested that the "simplest rules of thumb are $N \geq 50+8 m$ (where $m$ is the number of IVs) for testing the multiple correlation and $N$ $\geq 104+m$ for testing individual predictors" (p. 117). In this study there will be eight predictor variables. Following Tabachnick and Fidell's guidelines, at least 112 responses are necessary for testing the multiple correlations; thus, the 158 student records provided a large enough sample for this study.

The student population at this medical campus was representative of what could be observed in the enrollment at the other seven campuses. In fact, students who come to the medical campus have already completed prerequisite coursework in general education at one of the other campuses. For the medical technology program, students must have completed the first college English course (1101) and at least one of the science courses 
with lab that are part of the pre-requisites in the curriculum. This means that many of the incoming students have not completed all their prerequisite coursework and are expected to take those courses while in program.

According to statistical reports compiled by the college in this study, during the academic year 2007-2008, 54.7\% of students in the medical programs were Hispanic and $29.8 \%$ Black Non-Hispanic. This statistic is in comparison to $67 \%$ Hispanics and $20 \%$ Black Non-Hispanic across the institution. The majority of students in the medical programs are women, $59.4 \%$ with men comprising $40.6 \%$ of the student population. These gender statistics compare well with those across the institution, where $60 \%$ are women and $40 \%$ are men. While these demographic statistics seem to reflect the college's population, the same report shows only $24 \%$ of the credit students were pursuing an A.S. degree and 65\% an A.A. transfer degree. Examining the enrollment statistics of students at the college the researcher found that the age statistics were also of interest with $28.2 \%$ of the students falling between 25 and 30 years of age and almost as many $25.9 \%$ falling in the age category of 36 or older. This is significant because these older students are returning to school after years of being out in the workforce. Many of them may be emblematic of the economic challenges people face and now find themselves having to go back to school to find a new career path. Demographic information for the medical programs from the graduate report during the 2007-2008 academic year shows that $74.2 \%$ of graduates are female in contrast to $25.8 \%$ male. 


\section{Research Measures}

\section{ACCUPLACER/Computerized Placement Test (CPT)}

In the state of Florida, there is a requirement that students seeking an associate in arts or associate in science take an entry-level test to assess their proficiency in the areas of reading, writing, and math. Furthermore, the state of Florida also sets guidelines that determine when remedial work is required for students who do not meet minimum scores. The test currently used in placement decisions at the college is the ACCUPLACER College Placement Test (CPT). While all students coming in are required to take the test, there are students who are exempted from taking the CPT. For example, students who have earned an associate degree or higher from an accredited institution that is recognized by the college are exempt from the examination. Therefore, participants who did not take the CPT were not included in the sample. Data collection for CPT scores on participants was accomplished by using the scores reflected on the student transcript and obtained using the Odyssey Student Information System. CPT scores were used because they have been demonstrated to be an important indicator of college readiness (Mattern \& Packman, 2009).

\section{Cumulative GPA, Science GPA, and Professional First Semester GPA}

Cumulative GPA is part of the student's record and is available from the student's transcript. Science GPA was calculated from the grades earned on prerequisite science courses taken prior to coming into the program. Prerequisite natural science courses are: Human Anatomy and Physiology I and II with laboratories (BSC 2085, 3 credits and 2085L, 1 credit), (BSC 2086, 3 credits and 2086L, 1 credit), Introduction to Chemistry with lab (CHM 1025, 3 credits and 1025L, 1 credit) and Microbiology with lab (MCB 
2013, 3 credits and 2013L, 2 credits). In some cases, where students entered the program with the minimum natural science requirements, calculation of SGPA will only take into consideration the courses completed upon entering the program.

Professional first-semester GPA (PGPA) was calculated from the grades earned on MLT courses in the first semester of the program. First-semester courses for the medical laboratory program included Introduction to Medical Technology (MLT 1040L, 1 credit), Clinical Urinalysis (MLT 1210C - a combined course that has lecture and lab, 2 credits), Clinical Hematology Lecture (MLT 1300, 2 credits), Clinical Hematology Lab (MLT 1300L, 2 credits), and Laboratory Mathematics and Quality Control (MLT 1752, 2 credits).

\section{Dependent variable: Program Completion}

This variable represented whether an entering student completed the program within the prescribed 2 years. Completion was defined as completion of all prerequisite and program MLT courses, including the four clinical courses in the curriculum. All MLT courses had to be completed with a grade of "C" or better. A "C" in the medical laboratory technology program in this study was a minimum of $75 \%$. Students who successfully completed the program were assigned a value of "1." Students who left the program for any academic reason were coded as " 0 ".

\section{Independent Variables}

\section{Cumulative grade point average (CGPA)}

This variable represented the grade point average that was calculated from all coursework the student had attempted. This included courses that may have transferred from another institution of higher education. Courses included in calculating the grade 
point average were those that were attempted and completed. Courses where the student received an "incomplete (I)" or "withdraw (W)" were not part of the grade point average. At the college, courses that were assigned an "I" turn into an "F" should the student not meet the requirements or "complete" the course within the next semester when the course is offered. Calculation of the grade point average was based on the traditional point assignment $\mathrm{A}=4$ points, $\mathrm{B}=3$ points, $\mathrm{C}=2$ points, $\mathrm{D}=1$ point, $\mathrm{F}=0$ points. The formula used for calculating grade point average was as follows: Total Grade Points divided by Units Attempted. The units attempted were the semester credits for each course and the grade points correspond to the points for A, B, C, D, or F. Each course had an assigned number of credits that was multiplied by the point value of the assigned final grade. Multiplying the credits by the point value allowed the researcher to calculate the "Grade Points." The "Total Grade Points" were the sum of the "Grade Points" for each course. The "Units Attempted" or "Credits Attempted" was added. Once the researcher had the "Total Grade Points" and the "Units Attempted," she was able to calculate "Grade Point Average" or GPA.

\section{ACCUPLACER/Computerized Placement Test (CPT) Scores}

According to Mattern and Packman (2009), "the College Board's ACCUPLACER program, is a computer adaptive placement testing system used to assess students' knowledge and skills in a variety of subject areas" (p. 2). The purpose of the test is to measure whether the student comes with the necessary academic skills to pursue college or university-level work. The ACCUPLACER test includes assessments in English skills (sentence structure and reading comprehension). The test also includes a math assessment that encompasses arithmetic, college mathematics, and algebra. The academic level 
demonstrated by the student dictates whether the student needs remedial or developmental courses to improve certain academic skills.

The ACCUPLACER is a computer-adaptive test. This means that the student takes the test on the Internet. The test adjusts to the student's academic level, which means that questions are chosen based on the answers to previous questions and increase in difficulty as the test progresses until the student's level is determined. Students receive immediate feedback on their performance at the end of the test. Once the student completes the test, advisement follows with a prescription of recommended coursework that is based on academic ability.

The College Board is a not-for-profit member organization whose mission is to connect students to opportunity for an education and college success. The College Board was founded in 1900 and serves millions of students and participating institutions every year. The ACCUPLACER/Computerized Placement Test (CPT) is one the many products and services the College Board provides to institutions as a way to better serve the student populations with placement into courses that best fit their academic level. According to Mattern and Packman (2009), in a College Board Research Report, "the main goal of placement testing is to enroll students in courses that are aptly challenging to their current knowledge level so as not to bore or frustrate, which can lower motivation to perform" (p. 1). The goal of the study was to "meta-analyze a large sample of placement studies to estimate the true validity of placement decisions by correcting for statistical artifacts" (Mattern \& Packman, p. 2). Statistical artifacts were identified by the researchers in the study as sampling error and measurement error and pointed to the problems with downward-biased estimates when the data was not corrected for these 
errors. The data for the study came from all ACCUPLACER validity studies completed between 2001 and 2006. The studies included in this meta-analysis Mattern \& Packman (2009) "were analyzed to determine the overall relationship between ACCUPLACER test scores and success in postsecondary courses across institutions" (p. 2). There were 47 ACCUPLACER validity studies included in this meta-analysis, with $82.4 \%$ of the data used in the studies coming from community colleges.

The results of the study allowed Mattern and Packman (2009) to conclude that, "there was a moderately-to-strong relationship between test scores and course success, demonstrating that ACCUPLACER test scores provide utility in terms of placing students into courses in which they are likely to succeed" (p. 1). Additionally, the researchers indicated that the study provided a valuable source of information regarding the validity of the ACCUPLACER as a tool that could be used in course placement decisions. Furthermore, while there was a wealth of studies examining the predictive validity of placement tests such as the SAT and ACT, there is little known about the ACCUPLACER tests. In fact, Mattern and Packman (2009) suggested "the studies that have examined the placement validity of various measures [in the ACCUPLACER] often fail to correct for statistical artifacts that attenuate the results" (p. 6). Therefore, the fact that the Mattern and Packman study examined a number of previous investigative research studies looking at the predictive value of the ACCUPLACER, coupled with their use of statistical correction makes this a valuable piece of research into the predictive validity of the ACCUPLACER test.

Score ranges as prescribed under ACCUPLACER placement guidelines for 20082009 showed that in the Reading Section, students must score between 83 and 120 to be 
exempt from taking remedial courses and to be eligible for English 1101 (ENC 1101).

Students must also score between 83 and 120 in the Writing Section of the examination. Students who placed between 20 and 82 in both the Reading and Writing sections had to do remedial work. The following table reflects the breakdown of the grades and was based on the 2008-2009 Course Placement Guide:

Table 2

ACCUPLACER College Placement Guide Reading and Writing 2008-2009

\begin{tabular}{clcc}
\hline \multicolumn{2}{c}{ Reading } & \multicolumn{2}{c}{ Writing } \\
\hline $20-50$ & Reading REA 001 & $20-50$ & English ENC 0002 \\
$51-70$ & Reading REA 002 & $51-70$ & English ENC 0020 \\
$71-82$ & Reading REA 003 & $71-82$ & English ENC 0021 \\
$83-120$ & Exempt & $83-120$ & English ENC 1101 \\
\hline
\end{tabular}

In the Mathematics section, placement can be based on a combination of tests. Students attempt the Algebra section of the examination and obtain a score that can range from 20 to 120. Students scoring between 20 and 71 on the Algebra subset of the examination must take the Arithmetic examination. The following table shows the breakdown of scores for Mathematics and suggested placement based on the scores. 
Table 3

ACCUPLACER College Placement Guide Math 2008-2009

\begin{tabular}{llll}
\hline Algebra Score & Arithmetic Score & $\begin{array}{l}\text { College-Level Math } \\
\text { Score }\end{array}$ & Required Placement \\
\hline $20-71$ & $20-29$ & Not Required & MAT 0002 \\
$20-71$ & $30-64$ & Not Required & MAT 0020 \\
$20-71$ & $65-120$ & Not Required & MAT 0024 \\
$72-86$ & Not Required & Not Required ${ }^{(1)}$ & MAT 1033 \\
$87-120$ & Not Required & $20-39$ & MAT 1033 \\
$87-120$ & Not Required & $40-62$ & $\begin{array}{l}\text { MAC 1105, or MGF } \\
1106, \text { or MGF 1107 }\end{array}$ \\
$87-120$ & & & Refer to \\
& Not Required & $63-120$ & $\begin{array}{l}\text { Mathematics } \\
\text { Department }\end{array}$
\end{tabular}

${ }^{1}$ College-Level Mathematics subset examination is available upon request. Students who are registered for a mathematics course (and are past the 100\% refund deadline) are not eligible to take the College-Level Mathematics subset without permission from the administration in the Mathematics department.

Students can either place below the acceptable score, meaning the student must do remedial work or can place at college level. Students were be coded "0" if they took the exam and were placed in remedial courses. Those who took the exam and placed at college level or were not required to take the exam were coded " 1 ."

Science Grade Point Average (SGPA)

The amount of science completed prior to admission was used as a predictor of completion. This variable represented the grade point average calculated from the prerequisite science courses the student took prior to starting the program. Because many students do not start the program with all their science prerequisites, the SGPA was 
calculated from those courses the students completed. Courses where the student received an "incomplete (I)" or "withdraw (W)" were not part of the science grade point average. The calculation of the Science Grade Point is based on the traditional point assignment $\mathrm{A}=4$ points, $\mathrm{B}=3$ points, $\mathrm{C}=2$ points, $\mathrm{D}=1$ point, $\mathrm{F}=0$ points. The formula for calculating science grade point average was as follows: Total Grade Points divided by Units Attempted. The units attempted are the semester credits for each course and the grade points correspond to the points for A, B, C, D, or F. Each course was assigned a number of credits that was multiplied by the point value of the assigned final grade. Multiplying the credits by the point value allowed the researcher to calculate the "Grade Points". The "Total Grade Points" were the sum of the "Grade Points" for each course. The "Units Attempted" or "Credits Attempted" was added. Once you the "Total Grade Points" and the "Units Attempted" for the science courses were calculated, the researcher was able to calculate "Science Grade Point Average" or SGPA.

\section{Professional Grade Point Average after the First Semester (PGPA)}

This variable was calculated from the medical laboratory courses the student completed on the first semester. The variable did not include general education courses taken within the semester. All program courses have an "MLT" prefix, which is unique to the medical laboratory program. This prefix was not used by any general education or other health science course. The following were courses that were considered in the calculation of Professional GPA (PGPA). These courses comprised the first semester of the medical laboratory technology courses in the curriculum. The courses were as follows: MLT 1040L Introduction to Medical Laboratory Technology, MLT 1300 
Hematology Lecture, MLT 1300L Hematology Laboratory, MLT 1200C Urinalysis and Body Fluids, MLT 1752 Laboratory Mathematics and Quality Control.

$$
\text { Age }
$$

The age variable represented the years of age of the participant selected from a range of ages. Those 25 to 35 years of age were coded "1"; 36 to 40 were coded " 2 "; and, 41 to 60 were coded " 3 ."

\section{Language}

This demographic variable represented the student's native language. Students were coded " 0 " if their native language was not English. Those whose native language was English were coded "1".

\section{Gender}

This demographic variable represented whether the student was male or female. Students were coded " 0 " if male and " 1 " if female. .

\section{Ethnic Origin}

Ethnic origin represents the student's ethnic origin (White, Hispanic, African American, Caribbean). Ethnic origin was coded as follows: "1" = African American, "2" = Hispanic, " $3 "=$ White, and " $4 "=$ Caribbean.

\section{Data Collection}

Data collection for this study commenced upon approval by the dissertation committee, the university IRB office, and the University Graduate School at Florida International University (FIU). Authorization for the collection of data was also secured from district administration at the college. The FIU IRB approved proposal was 
submitted to the Director of Institutional Research and the College Academic and Student Services Council (CAASC) Research and Testing Committee. The FIU Institutional Review Board (IRB) application and approval was secured prior to data collection. Full approval from the college's Research and Testing Committee was also secured. All data was kept confidential. The data that was used for this study was stored electronically and available through the Student Tracking and Odyssey systems. The Odyssey system is an integrated online database that is used internally in the day to-day operations of the college. The system has several functional areas that are used for payroll, budgeting, and the like. Included in these functional areas is the Student Information System where one can access student records, such as transcripts and degree audits. All the data that was used for this study was available from the Student Information System on Odyssey. Because Odyssey is an internal system, there is no access outside of the campus. Therefore, the researcher collected the data on-campus. The data was kept on a USB flash drive with one backup copy. Files with student data were encrypted with a password for maximum security. The timeline for the collection of the data was set at 8 to 10 weeks. Data collection was completed in 8 weeks.

\section{Data Analysis}

After first using descriptive data analysis procedures to examine the data, the research questions were answered using a logistic regression model. This statistical model was chosen because of its ability to analyze binary response variables. In this case, the binary variable was whether or not a student admitted to the program had completed 
it. The number " 0 " was recorded for students who did not complete the program; " 1 " was recorded for students who completed the program within 2 years.

\section{Summary}

In summary, a retrospective logistic regression analysis design was used to study the relationship between the independent variables (i.e., Cumulative GPA, Science GPA, CPT Math and CPT Reading scores, and Professional GPA), and success in the program as expressed by Completion of the Medical Laboratory Technology program within two years. Data collection was accomplished by a review of student records for the years 2000-2010. All data were entered into an Excel worksheet, imported into SPSS 19.0, and analyzed using a range of statistical techniques, including logistic regression analysis. 


\section{CHAPTER IV}

\section{RESULTS}

This chapter presents the results of the study and provides the data and analysis used to answer the research question and subquestions. The study was guided by one research question and four subquestions. The research question asked, what student characteristics best predict successful completion of the Medical Laboratory Technology program? The subquestions asked the following:

1. What academic preparation factors (College Placement Test, Cumulative GPA, Science GPA, and Professional GPA), are predictors of program completion?

2. Which demographic factors (gender, ethnicity, and age) are predictors of program completion?

3. To what degree does performance on the CPT predict program completion?

4. To what degree does GPA (Cumulative GPA, Science GPA, and Professional GPA) predict program completion?

\section{Description of the Sample}

A total of 158 academic records were reviewed $(N=158)$, comprising graduates from the associate in science degree program in medical laboratory technology of the selected college (i.e., the entire population was reviewed). The study considered records for students declaring their major between 2000 and 2010. The records selected were comprised of students ranging in age from 25 to 60. Most of the students were female and either Hispanic or Black from the Caribbean. Because all of the data was complete, the researcher was able to utilize each student from the entire time period being investigated. 
The importance of this is that there was that selection bias was not an issue in this research (Tabachnick \& Fidell, 2001).

\section{Analysis of the Variables}

Demographic and background characteristics were analyzed using descriptive statistics that included frequencies and percentages. Independent variables were also analyzed using descriptive statistics such as ranges, means, and standard deviations. Cross tabulations were conducted to assess the relationships among the demographic variables. The Pearson chi-square significance test was performed using the demographic variable combinations with the goal of determining if there were any statistical differences between the distributions.

Moreover, correlational analysis was performed to determine the strength and the direction of the relations among the research variables (Cumulative GPA, Science GPA, CPT Math, CPT Reading, and Professional GPA) and Completion and Time to Completion. ANOVAs were conducted to examine the possible differences between group means for the research variables by age, gender, and ethnic origin. Possible interactions were tested as well. Finally, binary logistic regression was performed to test each of the research subquestions.

\section{Description of the Demographic and Academic Variables}

The information from the student's demographic and academic information, that is, age, language, gender, ethnicity, ethnic origin, cumulative GPA, science GPA, professional GPA, completion, and time to completion is examined in the following sections. 
A frequency analysis of age indicated that $83.5 \%(n=132)$ of the students belonged to the 25 to 35 age group, $11.4 \%(n=18)$ to the 36 to 40 group, $4.4 \%(n=7)$ to the 41 to 50 group, and finally $0.6 \%(n=1)$ to the 51 to 60 age group.

\section{Language}

A frequency analysis of the primary language of the student sample used in this study indicated that $77.8 \%(n=123)$ spoke a primary language other than English, and $22.2 \%(n=35)$ were students whose primary language was English. The high percentage of students who spoke a primary language other than English was comprised of students whose first language was either Spanish or French for those students originally from Haiti.

\section{Gender}

A frequency analysis of gender indicated that the student sample was $75.3 \%(n=$ 119) female and $24.7 \%(n=39)$ male.

\section{Ethnic Origin}

An empirical analysis of the data on ethnicity revealed the need to further divide the black students into two separate groups. This analysis revealed that a significant number of the Black students, $31.0 \%(n=49)$ were of Caribbean origin, as opposed to 15.2\% $(n=24)$ African American. There was $1(0.6 \%)$ Black student from the continent of Africa; the researcher added this student to the African American total. Thus, for the purposes of this study, there was a total of 25 African Americans (15.8\%). The ethnic origin variable was coded as follows: "1" for African American, "2" for Hispanic, "3" for White, and "4" for Caribbean. 


\section{Cumulative GPA (CGPA)}

Descriptive statistics of the data on Cumulative GPA revealed an average of 2.97 with a standard deviation of 0.41 and a range of $2.12-3.90$.

\section{Science GPA (SGPA)}

Descriptive statistics of the data on Science GPA revealed an average of 2.42 with a standard deviation of 0.72 and a range of $0.89-4.00$.

\section{Professional GPA (PGPA)}

Descriptive statistics of the data on Professional GPA revealed an average of 2.68 with a standard deviation of 0.85 and a range of $0.80-4.00$.

\section{Completion}

A frequency analysis of completion indicated that $69.0 \%(n=109)$ of the students completed the program in 2 years and $31.0 \%(n=49)$ did not.

\section{Time to Completion}

A frequency analysis of time to completion indicated that $50.6 \%(n=80)$ of the students completed the program within the prescribed 2 years and $18.9 \%(n=30)$ of the students within 3 years of declaring their major. Students completing between 4 and 8 years comprised $16.5 \%(n=26)$ of the sample. The remaining $13.3 \%(n=21)$ was comprised of students who had not completed.

Table 4 presents the means, standard deviations, and ranges for CGPA, SGPA, and PGPA. Table 5 presents the frequency of all the demographic factors examined in this study.

Table 4 Descriptive Statistics for Academic Variables CGPA, SGPA, and PGPA 


\begin{tabular}{lclcl}
\hline Variable & $N$ & Range & $M$ & $S D$ \\
\hline CGPA & 158 & $2.12-3.90$ & 2.97 & 0.41 \\
SGPA & 158 & $0.89-4.00$ & 2.42 & 0.72 \\
PGPA & 158 & $0.80-4.00$ & 2.68 & 0.85 \\
\hline
\end{tabular}

Table 5

Frequency Table of Demographic Variables

\begin{tabular}{llrr} 
Category & Variable & $f$ & Percent \\
\hline Age & $25-35$ & 133 & 84.2 \\
& $36-40$ & 17 & 10.8 \\
& $41-50$ & 7 & 4.4 \\
& $51-60$ & 1 & 0.6 \\
& Total & 158 & 100.0 \\
\hline \multirow{2}{*}{ Ethnicity } & Male & 39 & 24.7 \\
& Female & 119 & 75.3 \\
& Total & 158 & 100.0 \\
& African American & 74 & 46.8 \\
& Hispanic & 67 & 42.4 \\
& Caucasian & 17 & 10.8 \\
& Total & 158 & 100.0 \\
& & & \\
\hline \multirow{2}{*}{ Ethnic Origin } & African (Black) & 1 & 0.6 \\
& African American & 24 & 15.2 \\
& Hispanic & 67 & 42.4 \\
& Caribbean (Black) & 49 & 31.0 \\
& Caucasian & 17 & 10.8 \\
& Total & 158 & 100.0 \\
\hline Language & English & 35 & 22.2 \\
& Other & 123 & 77.8
\end{tabular}

Table 6 provides the cross tabulation of demographic variables age, ethnic origin, language, and gender. The chi-square statistic was used to determine if the demographic 
factors (age, gender, ethnic origin and language) were systematically different. The results of the chi-square tests for the variable combinations of the demographic factors revealed no statistical differences between distributions of each sample at the $\alpha=.05$ level.

Table 6

Demographic Variable Cross Tabulation

\begin{tabular}{lccc}
\hline Variable Combination & $\chi^{2}$ Value & $d f$ & $p$ \\
\hline Age and Ethnic Origin & 1.25 & 6 & .975 \\
Age and Language & 0.26 & 2 & .876 \\
Gender and Ethnic Origin & 1.47 & 3 & .890 \\
Gender and Language & 0.39 & 1 & .545 \\
\hline
\end{tabular}

Correlational Analysis

To explore the strength and direction of relation among the research variables, correlational analyses (Pearson's $r$ for continuous variables; Spearman's rho for dichotomous variables) were performed (see Table 7). There were two dependent variables: Completion and Time to Completion. Completion was defined as either completing the program or not within 2 years. Time to Completion was defined as time in years to complete the program. The correlational analysis for completion revealed positive statistically significant relations between Cumulative GPA (CGPA) $(r=.20, p<$ 
$.01)$, Science GPA (SGPA) $(r=.18, p<.05)$, College Placement Test (CPT) Math $(r=$ $.25, p<.001)$, and Professional GPA (PGPA) $(r=.38, p<.01)$. There was no statistically significant relation between CPT Reading and Completion $(r=.09, p>.05)$. Thus, students with higher CGPA, SGPA, CPT Math, and PGPA were more likely to complete their degree in 2 years. Further, correlational analysis between the variables and time to completion revealed negative statistically significant relations between CGPA ( $r$ $=-.21, p<.01)$, SGPA $(r=-.15, p<.05)$, CPT Math $(r=-.21, p<.001)$, CPT Reading $(r=-.16, p<.05)$ and PGPA $(r=-.31, p<.01)$. Thus, students with a lower CGPA, SGPA, CPT Math, CPT Reading, and PGPA were more likely to take additional time to complete their degree. Furthermore, correlational analysis between age and completion revealed a negative statistically significant relation $(r=-.14, p<.05)$. Thus, older students were slightly less likely to complete their program in two years. In contrast, age was not statistically significantly related $(r=-.07, p>.05)$ with the Time to Completion variable.

Table 7

Correlation Coefficients for Completion, Time to Completion, and Age. 


\begin{tabular}{lllllllll}
\hline Variable & CGPA & SGPA & CPTM & CPTR & PGPA & Comp & TComp & Age \\
\hline CGPA & -- & & & & & & & \\
SGPA & $.729^{* *}$ & -- & & & & & & \\
CPTM & $.373^{* *}$ & $.428^{* *}$ & -- & & & & & \\
CPTR & $.356^{* *}$ & $.238^{* *}$ & $.404^{* *}$ & -- & & & & \\
PGPA & $.619^{* *}$ & $.485^{* *}$ & $.467^{* *}$ & $.449^{* *}$ & -- & & & \\
Comp & $.202^{* *}$ & $.182^{*}$ & $.246^{* *}$ & .090 & $.376^{* *}$ & -- & & \\
TComp & $-.208^{* *}$ & $-.150^{*}$ & $-.210^{* *}$ & $-.163 *$ & $-.310^{* *}$ & $-.449^{* *}$ & -- & \\
Age & .028 & .098 & -.045 & -.072 & -.033 & $-.142^{*}$ & .071 & -- \\
\hline
\end{tabular}

Note. ${ }^{*} p<.05,{ }^{* *} p<.01$. CGPA $=$ Cumulative Grade Point Average. SGPA $=$ Science Grade Point Average. CPT Math $=$ College Placement Test Math. CPTR $=$ College Placement Test Reading. PGPA $=$ Professional Grade Point Average. Comp $=$ Completion. TComp $=$ Time to Completion. $N=158$

\section{Group Mean Differences}

In the preliminary stages of data analysis, researchers often recommend exploring data for possible group differences among the variables of interest in a study (Tabachnick $\&$ Fidell, 2001). In the case of this research, the research variables were examined for possible group mean differences in age, gender, and ethnic origin. These variables were selected because theory (e.g., Bean \& Metzner, 1985) and prior research in nursing (e.g., Newman \& Williams, 2003) suggested that demographic group differences may be linked meaningfully to educational outcomes such as those being examined in this research. The results are presented in Tables 8 through 10 . 
In Table 8, the one-way ANOVA results revealed no statistically significant group mean differences in any of the independent variables or program completion by age. Age was coded as $1=25-35$ years of age; $2=36-40$; and, $3=41-60$.

Table 8

Analysis of Variance of Group Mean Differences by Age

\begin{tabular}{lccc}
\hline Source & $D f$ & $F$ & $P$ \\
\hline & \multicolumn{2}{c}{ Between groups } & \\
CGPA & 2 & .114 & .893 \\
SGPA & 2 & 1.968 & .143 \\
CPT Math & 2 & .738 & .480 \\
CPT Reading & 2 & .479 & .620 \\
PGPA & 2 & .212 & .809 \\
Completion & 2 & 2.078 & .129 \\
& & & \\
\hline
\end{tabular}

When examining for group differences by age, gender, and ethnic origin, the three-way ANOVA main effect results revealed that CGPA, SGPA, CPT Reading, and PGPA differed significantly among individuals with different ethnic origins, but CPT Math and Completion (the dependent variable in this study) did not. In addition, a significant interaction effect was found between gender and ethnicity for the CPT Reading variable. The effect size estimates $\left(\right.$ partial $\eta^{2}$ ) in all cases suggested relatively low strength in associations. Bonferroni's post hoc tests were conducted to ascertain 
which ethnic origin group differed significantly for each variable that demonstrated a main effect (Tabachnick \& Fidell, 2001). For CGPA, the White participants demonstrated significantly higher group means than the African American group; both the White and Hispanic groups demonstrated higher CPGAs than the Caribbean group. With SGPA, mirroring the CGPA results, the White group had higher SGPA scores than the African American group and the White and Hispanic groups had higher SGPA scores than the Caribbean group. For CPT Reading, both the White and Hispanic groups demonstrated significantly higher reading scores than the Caribbean group. The gender $\mathrm{x}$ ethnic origin interaction revealed that the Hispanic males had significantly higher reading scores than the African American and Caribbean females. PGPA scores were significantly higher for the White group as compared to the African-American group; both Hispanic and White group scores were also significantly higher than the Caribbean group scores. Table 9 shows the results of the three-way analysis of variance (ANOVA) for the research variables with the demographic factors. To be clear, the researcher tested for age, gender, and ethnic origin differences based on prior research suggesting that these interactions may be present in studies of this nature (e.g., Bean \& Metzer, 1985). 
Table 9

Three-Way Analysis of Variance Results for Research Variables

\begin{tabular}{|c|c|c|c|}
\hline & $F$ & $P$ & $\eta^{2}$ \\
\hline \multicolumn{4}{|l|}{ CGPA } \\
\hline Age & .301 & .741 & .004 \\
\hline Gender & .102 & .750 & .001 \\
\hline Ethnicity & 3.676 & .014 & .040 \\
\hline Age x Gender & .126 & .882 & .002 \\
\hline Age $x$ Ethnic & 1.088 & .373 & .045 \\
\hline Gender x Ethnic & 1.150 & .217 & .032 \\
\hline Age $x$ Gender $x$ Ethnic & 1.806 & .149 & .038 \\
\hline \multicolumn{4}{|l|}{ SGPA } \\
\hline Age & 1.154 & .224 & .022 \\
\hline Gender & .853 & .357 & .006 \\
\hline Ethnic & 3.416 & .019 & .070 \\
\hline Age x Gender & .624 & .537 & .009 \\
\hline Age $x$ Ethnic & 1.059 & .390 & .044 \\
\hline Age $x$ Gender x Ethnic & 1.469 & .226 & .031 \\
\hline \multicolumn{4}{|l|}{ CPT Math } \\
\hline Age & .421 & .657 & .006 \\
\hline Gender & .109 & .742 & .001 \\
\hline
\end{tabular}




\begin{tabular}{|c|c|c|c|}
\hline & $F$ & $P$ & $\eta^{2}$ \\
\hline Ethnic & .078 & .972 & .002 \\
\hline Age x Gender & .355 & .702 & .005 \\
\hline Age $\mathrm{x}$ Ethnic & .662 & .712 & .027 \\
\hline Gender x Ethnic & 2.126 & .068 & .042 \\
\hline Age x Gender x Ethnic & .326 & .807 & .007 \\
\hline \multicolumn{4}{|l|}{ CPT Reading } \\
\hline Age & .513 & .600 & .007 \\
\hline Gender & 3.170 & .077 & .023 \\
\hline Ethnic & 2.845 & .040 & .059 \\
\hline Age x Gender & .366 & .694 & .005 \\
\hline Age $x$ Ethnic & 1.031 & .408 & .043 \\
\hline Gender x Ethnic & 2.741 & .046 & .057 \\
\hline Age x Gender x Ethnic & .569 & .619 & .013 \\
\hline \multicolumn{4}{|l|}{ PGPA } \\
\hline Age & 1.368 & .258 & .020 \\
\hline Gender & 2.112 & .148 & .015 \\
\hline Ethnic & 3.064 & .030 & .063 \\
\hline Age x Gender & 1.075 & .344 & .015 \\
\hline Age $x$ Ethnic & .651 & .689 & .028 \\
\hline
\end{tabular}




\begin{tabular}{llll}
\hline & $F$ & $P$ & $\eta^{2}$ \\
Gender x Ethnic & 2.214 & .077 & .044 \\
Age x Gender x Ethnic & 2.404 & .070 & .050 \\
\hline & & & \\
Completion & & & \\
Age & 1.702 & .186 & .024 \\
Gender & 2.028 & .157 & .015 \\
Ethnic & 1.362 & .257 & .029 \\
Age x Gender & .626 & .536 & .009 \\
Age x Ethnic & 1.620 & .146 & .066 \\
Gender x Ethnic & 1.337 & .265 & .028 \\
Age x Gender x Ethnic & .278 & .841 & .006 \\
\hline
\end{tabular}

Binary Logistic Regression

By definition, the logistic regression model assumes a categorical (qualitative) underlying distribution. Yang (2002) described the central mathematical concept that underlies logistic regression as the logit and called it "the natural logarithm of an odds ratio" (p. 3). In this study, the dichotomous outcome, Completion, was a coded as 0 or 1 $(0=$ Did Not Complete; 1 = Complete $)$.

The logistic regression equation was used to determine the probability of completing or not completing the program based on the combination of academic predictor variables (Cumulative GPA, Science GPA, CPT Math, CPT Reading, and 
Professional GPA) and demographic variables (Age, Gender, Ethnic Origin). The logistic regression models examined these academic and demographic variables as predictors of program completion as well as the degree to which the variables were responsible for predicting program completion.

In logistic regression analysis, the -2 Log likelihood value is a measure of how well the estimated model fits the likelihood. Because the likelihood is a small number less than 1 , likelihood is usually used as the -2 times the log likelihood in examining how well the model fits the data. The definition of a good model is one where there is a high likelihood of the observed results, which translates into a small value for the $-2 \log$ likelihood. A model that has a perfect fit has likelihood equal to one, and $-2 \log$ likelihood equal to zero. DeMaris (1995) pointed to the model chi-square test as the global test in logistic regression. Furthermore, he describes "the likelihood function as the joint probability of observing the current sample values of $Y$, given the parameters of the model" (p. 959).

The Cox $\&$ Snell $R$ Square is often referred to as a pseudo- $R$ Square and is based on the log-likelihood; it takes sample size into account and can only reach a maximum of 0.75 . On the other hand, the Nagelkerke $R$ Square, also a pseudo- $R$ Square, is an adjustment of the Cox \& Snell $R$ Square for the maximum value so that 1 can be achieved. It can be interpreted in the same manner as the $R^{2}$ for multiple linear regressions. As indicated by Steyerberg et al. (2010), the Nagelkerke $R$ Square "is a calculation that is based on the $-2 \log$ likelihood of a model without, and a model with one or more predictors" (p. 129). Finally, multicollinearity was tested via the Variance Inflation Factor (VIF) analysis (Tabachnick \& Fidell, 2001). All the VIF coefficients 
were less than 5.5; less than 10.0 is desirable. Thus, there is little evidence that multicollinearity was a significant issue in this research.

\section{Research Subquestion 1}

The first research question sought to determine whether the academic preparation factors (Cumulative GPA, Science GPA, CPT Math, CPT Reading, and Professional GPA) were predictors of program completion. For this research question, the Cox \& Snell $R$ Square was $.154(p<.001)$ and the Nagelkerke $R$ Square was $.242(p<.001)$. While the data analysis results showed a value for the $-2 \log$ likelihood equal to 132.847 , the overall "global" test of the model as represented by chi-square was equal to 26.383 ( $p$ $=.000)$, resulting in a statistically significant binary logistic regression model.

The binary logistic regression model with the academic independent variables (Cumulative GPA, Science GPA, CPT Math, CPT Reading, and Professional GPA) and the dependent variable Completion yielded results showing Professional GPA as the best predictor of completion with $(p=.001)$. Therefore, as Professional GPA increased, students were more likely to complete their program. The odds-ratio or $\operatorname{Exp}(\beta)$ provided an additional means to interpret the findings. The odds ratio for Professional GPA was 3.473, which indicated that for each one unit change in Professional GPA, students were 3.473 times more likely to complete the program. Cumulative GPA, Science GPA, CPT Math, and CPT Reading were not significant predictors of completion in the model. Additionally, the regression model predicted $81 \%$ of the cases for program completion. Table 10 shows the results of the binary logistic regression model for research subquestion 1. 
Table 10

Summary of Logistic Regression Analysis of Academic Independent Variables Predicting Completion in Research Question One

\begin{tabular}{|c|c|c|c|c|c|}
\hline \multirow[b]{2}{*}{ Predictor } & \multicolumn{5}{|c|}{ Completion } \\
\hline & $B$ & $S E B$ & Wald & $\operatorname{Exp}(\beta)$ & $P$ \\
\hline CPT Math & .804 & .552 & 2.118 & 2.234 & .146 \\
\hline CPT Reading & -.778 & .563 & 1.912 & .459 & .167 \\
\hline Cumulative GPA & -.010 & .874 & .000 & .990 & .991 \\
\hline Science GPA & -.056 & .466 & .014 & .946 & .905 \\
\hline Professional GPA & 1.245 & .370 & 11.301 & 3.473 & .001 \\
\hline Constant & -1.584 & 1.833 & .747 & .205 & .387 \\
\hline$\chi^{2}$ & 26.383 & & & & .000 \\
\hline$d f$ & 5 & & & 5 & \\
\hline
\end{tabular}

Note: $\operatorname{Exp}(\beta)=$ odds ratio. Completion was coded as 1 for yes and 0 for no.

\section{Research Subquestion 2}

The second research subquestion sought to determine whether the demographic factors (age, gender, and ethnic origin) were predictors of program completion. For this logistic regression model, the -2 Log-likelihood was 152.955 , indicating a relatively poor fit of the model to the data. The overall test of the model as represented by chi-square was $6.274(p=.099)$, resulting in a binary logistic regression model that was not statistically significant. 
The Cox \& Snell $R$ square value was .039 and Nagelkerke $R$ Square was .061 . The binary logistic regression model with all demographic independent variables (age, gender, and ethnic origin) and the dependent variable Completion yielded results showing no statistical significance at the $\alpha=.05$ level. Therefore, the demographic variables were not significant predictors of program completion. The regression model successfully predicted $81.0 \%$ of the cases for program completion. Table 11 presents the results of the regression model for research subquestion 2 .

Table 11

Summary of Logistic Regression Analysis for Demographic Independent Variables Predicting Completion in Research Subquestion 2

Completion

\begin{tabular}{ccccc}
\multicolumn{5}{c}{ Completion } \\
\hline & $S E B$ & Wald & $\operatorname{Exp}(\beta)$ & $P$ \\
-.523 & .353 & 2.189 & -.593 & .139 \\
.732 & .434 & 2.846 & 2.080 & .092 \\
-.166 & .187 & .784 & .847 & .376 \\
1.935 & .765 & 6.397 & 6.922 & .011 \\
6.274 & & & & .099 \\
3 & & & 3 &
\end{tabular}

Note: $\operatorname{Exp}(\beta)=$ odds ratio. Completion was coded as 1 for yes and 0 for $n o$. Ethnic origin was dummy coded as 1 as African American, 2 as Hispanic, 3 as White and 4 as Caribbean. The "White" variable served as the comparison variable. 


\section{Research Subquestion 3}

The third research subquestion sought to predict the degree to which completion could be predicted from performance on CPT Math and CPT Reading. For this binary logistic regression model, the -2 Log-likelihood was 149.305 , indicate a relatively poor model fit to the data. However, in this case, the overall test of the model as represented by chi-square was $9.925(p=.007)$, indicating a statistically significant regression model. The Cox \& Snell $R$ square value was .061 $(p<.05)$ and Nagelkerke $R$ Square was .096 ( $p$ $<.05)$. The binary logistic regression model with the academic independent variables (CPT Math and CPT Reading), and the dependent variable Completion yielded results showing that performance on the CPT Math had a significant impact on Completion ( $p=$ .006). The odds ratio for CPT Math was 3.852, which indicated that for each one unit change in CPT Math scores, students were 3.852 times more likely to complete the program. The regression model correctly predicted $79.7 \%$ of the cases for program completion. Table 12 shows the results of the binary logistic regression model for research subquestion 3 . 
Table 12

Summary of Logistic Regression Analysis of Variables Predicting the Extent to which Performance on CPT Math and CPT Reading Predicted Completion

\begin{tabular}{lcccccc}
\hline & \multicolumn{7}{c}{ Completion } \\
\cline { 2 - 6 } Predictor & \multicolumn{7}{c}{ SE $B$} & Wald & $\operatorname{Exp}(\beta)$ & $P$ \\
\hline CPT Math & 1.349 & .486 & 7.691 & 3.852 & .006 \\
CPT Reading & -.068 & .487 & .020 & .934 & .888 \\
Constant & .859 & .259 & 11.004 & 2.362 & .001 \\
$\chi^{2}$ & 9.925 & & & & .007 \\
Df & & & & & \\
\end{tabular}

Note: $\operatorname{Exp}(\beta)=$ odds ratio. Completion was coded as1 for yes and 0 for no.

Research Subquestion 4

The fourth research subquestion, sought to predict the degree to which completion could be predicted from the independent variables (Cumulative GPA, Science GPA, and Professional GPA). For this logistic regression model, the -2 Log-likelihood was 136.068, indicating a relatively poor fit of the model to the data. However, once again in this case, the overall test of the model as represented by chi-square was $23.162(p=.000)$, indicating a statistically significant regression model. The Cox \& Snell $R$ square value was .136 $(p<$ $.001)$ and Nagelkerke $R$ Square was $.215(p<.001)$. The binary logistic regression model with the academic independent variables (Cumulative GPA, Science GPA, and Professional GPA) and the dependent variable Completion yielded results showing Professional GPA as the variable with the highest impact on Completion $(p<.001)$. The 
odds ratio for Professional GPA was 3.454, which indicates that for each one unit change in Professional GPA, students were 3.454 times more likely to complete the program. The regression model predicted $79.7 \%$ of the cases for program completion. Table 13 shows the results of the binary logistic regression model for research sub-question four.

\section{Table 13}

Summary of Logistic Regression Analysis of Variables Predicting the Extent to which Cumulative GPA, Science GPA, and Professional GPA Predicted Completion

\begin{tabular}{lccccc}
\hline & \multicolumn{5}{c}{ Completion } \\
\cline { 2 - 6 } Predictor & \multicolumn{7}{c}{ SE $B$} & Wald & $\operatorname{Exp}(\beta)$ & $P$ \\
\hline Cumulative GPA & -.264 & .858 & .095 & .768 & .758 \\
Science GPA & .161 & .445 & .130 & 1.174 & .718 \\
Professional GPA & 1.240 & .345 & 12.880 & 3.454 & .000 \\
Constant & -1.277 & 1.771 & .520 & .279 & .471 \\
$\chi^{2}$ & 23.162 & & & & .000 \\
Df & 2 & & & &
\end{tabular}

Note: $\operatorname{Exp}(\beta)=$ odds ratio. Completion was coded as 1 for yes and 0 for $n o$.

\section{Summary}

This study examined academic (Cumulative GPA, Science GPA, CPT Math, CPT Reading, and Professional GPA) and demographic (Age, Gender, and Ethnic Origin) predictors to determine their unique effect on Completion of an Associate in Science Medical Laboratory Technology program. Additionally, the study examined the extent to 
which the variables (CPT Math, CPT Reading, and Professional GPA) had an effect on completion of the Medical Laboratory Technology program.

Research subquestion 1 examined the academic factors to see if any of them were predictors of Completion. For this subquestion, the study findings indicated that Professional GPA was the only significant predictor of Completion. Research subquestion 2 examined the demographic factors to see if any were predictors of Completion. For this subquestion, none of the demographic factors were significant predictors of Completion. Research subquestion 3 examined the degree of impact on Completion from the performance on the CPT Math and CPT Reading. For this subquestion, performance on the CPT Math had predicted Completion. Furthermore, there was no impact on Completion from the performance on CPT Reading. Finally, Research Subquestion 4 examined the degree of impact on completion from Cumulative GPA, Science GPA, and Professional GPA. Once again, the study found Professional GPA was the sole significant predictor of program completion.

Chapter V discusses the conclusions drawn from these findings, the implications of these findings in increasing completion, as well as recommendations for possible future research. 


\section{CHAPTER V \\ DISCUSSION, CONCLUSIONS AND RECOMMENDATIONS}

The goal of this study was to identify student factors that are associated with successful completion of medical laboratory technology (MLT) programs. In this study, successful completion of the program of study encompassed timely completion defined as completion within the prescribed 2 years. This study was completed by examining possible academic predictors of success: Cumulative GPA (CGPA), Science GPA (SGPA), College Placement Test Math (CPT Math), College Placement Test Reading (CPT Reading), and Professional GPA (PGPA), and demographic factors (i.e., age, gender, and ethnic origin).

\section{Summary of the Study}

Correlational analysis was performed to determine the strength and the direction of relations among CGPA, SGPA, CPT Math, CPT Reading, PGPA, and age, and program completion, the dependent variable. There were positive statistically significant relations between CGPA, SGPA, CPT Math, CPT Reading, PGPA and completion. Therefore, students with higher CGPA, SGPA, CPT Math, CPT Reading, and PGPA were more likely to complete the degree within the prescribed 2 years. In fact, of all the academic factors, Professional GPA demonstrated the strongest association with program completion. This is important because Professional GPA is a new predictor that has not been studied before as it relates to completion in a medical laboratory technology program. 
Correlational analysis of the relation between age and program completion revealed a negative statistically significant relation, indicating that older students were slightly less likely to complete the program within 2 years when compared to younger students. Still, the correlation was rather small $(r=-.15)$, reflecting that other variables may be worthy of study when considering older students' program completion. Yang (1997), for instance, reported on the positive effects of age and the evidence which “...suggests that older people are more committed to course work, less likely to be absent or show up late for class... and more active in raising questions and participating in discussions (p. 344).” Although the researcher cannot state this for certain, it may be that the older students participating in this research may have had a number of additional barriers to program completion like working more hours per week not only finance school but also to managing their households (Goodyear \& Lampe, 2004). Thus, fewer hours may have remained available to study and to complete coursework in a timely fashion, especially among the non-majority of females (Laudicina, 1999).

Age, gender, and ethnic origin were also analyzed to see if there were differences in the research variable scores (ANOVAS). Analysis of the data demonstrated that White students had higher Cumulative GPA, Science GPA, and CPT Reading scores, and Professional GPA as compared to the African American and Caribbean participants. Hispanic students, on the other hand, had higher Cumulative GPA, Science GPA, CPT Reading scores, and Professional GPA as compared to the Caribbean students. The interaction analyses showed also that Hispanic males had higher CPT Reading scores as compared to African American and Caribbean females. Separate examination of the CPT Math and CPT Reading scores and program completion yielded results showing that 
performance on the CPT Math had the highest association with program completion in the correlational analyses. Notwithstanding, Professional GPA (PGPA) was the best predictor of program completion with a binary logistic regression model, predicting $80 \%$ of the cases. The model also showed that students with a high Professional GPA were almost four times more likely to complete the program within the prescribed 2 years. This result is consistent with previous studies in the health sciences. For example, Campbell and Dickson (1996) did a 10-year review and meta-analysis of studies in nursing predicting student success, which showed "grade point averages in nursing and science courses [were] the greatest cognitive predictors of student success" (p. 47).

\section{Research Subquestion 1}

Research subquestion 1 asked what academic preparation factors (College Placement Test, Cumulative GPA, Science GPA, and Professional GPA) are predictors of program completion. Statistical analysis to answer this question revealed Professional GPA (grade point average in MLT courses in the first semester) was the strongest academic predictor of program completion. The logistic regression model for Professional GPA predicted program completion $79.1 \%$ of the time. This finding is consistent with the Bean and Metzner (1985) Conceptual Model of Nontraditional Student Attrition, which pointed to academic outcome variables such as GPA as affecting attrition. While the model does not specifically point to a specific type of GPA as found to be significant in this study (i.e., PGPA), it is noteworthy to point out that the results of this study supported the Bean and Metzner model.

In this study, the researcher constructed a framework based on the Bean and Metzner model and tested aspects of the model, such as background defining variables, 
and academic outcome variables that were found by Bean and Metzner to have a direct effect on attrition. In fact, in support of the findings in this study with respect to academic outcome, Bean and Metzner noted that the Conceptual Model of Nontraditional Student Attrition "indicates that students with poor academic performance are expected to drop out at higher rates than students who perform well, and GPA is expected to be based primarily on past (high school) academic performance" (p. 490). In the current study, past high school academic performance shown in the Bean and Metzner Model (1985) as background defining variables was reflected in the variables of CPT Math, and CPT Reading because these are assessments that test the students' knowledge base prior to taking college courses.

The findings resulting from this research subquestion are also consistent with Wong and Wong (1999) who studied predictors of success in a nursing program and found that "the risk of failure was nearly half as great among students with low GPA in the first year nursing courses in comparison with those whose first year nursing GPA was high” (p. 351). Other nursing researchers, such as Alexander and Brophy (1997), reported that specific GPAs were significant in predicting success on the NCLEX-RN" (p. 445).

The results of the researcher's study also support other studies that suggested the importance of GPA in discipline specific courses or professional GPA. Daley et al. (2003), for instance, examined nursing program variables in a baccalaureate nursing program and their relation to success on the National Council Licensure Examination for Registered Nurses (NCLEX-RN). Their findings clearly pointed to the grades on three discipline courses, pathophysiology and the didactic and clinical medical surgical nursing 
course, as being significantly different between the group of nursing students who successfully passed the NCLEX-RN and those who failed. The same researchers also studied the contribution of cumulative GPA and final grades in anatomy, which were found to be significantly higher for the group that passed the NCLEX-RN. It is interesting to note in this study, however, that Cumulative GPA and Science GPA were not found to be significant unique predictors of program success in the regression models.

Support for Professional GPA as a predictor can also be found with other studies in nursing. While not studied in relation to program completion, these studies are also significant. A study by Jeffreys (2007) found a strong correlation with academic variables and success on the NCLEX-RN. The researcher found that " $100 \%$ of students who achieved a "B" NCGA [nursing course grade average] passed the licensure on the first attempt" (p. 417). While some of these studies did not indicate whether the courses being examined were at the beginning or were later in the academic program or the extent of the contribution of these predictor courses on program completion, it did highlight the importance of grades in the discipline courses that ultimately determine Professional GPA.

While many studies (e.g., Potolsky et al., 2003; Wharrad et al., 2003; Wong and Wong, 1999) found grades in the basic sciences as expressed in Science GPA or prerequisite course grades as good academic predictors, this study did not find Science GPA or Cumulative GPA to be a significant predictor of program completion for the Medical Laboratory Technology program beyond Professional GPA. 


\section{Research Subquestion 2}

Research Subquestion 2 asked which demographic factors (gender, ethnic origin, and age) are predictors of program completion. For this subquestion, the findings revealed the demographic factors were not predictors of program completion. However, while demographics did not predict completion, there were some differences between the groups that are worth mentioning (findings related to ANOVA analyses).

Examination of the group differences by gender revealed statistically significant group mean differences in CPT reading scores, but not in CPT math scores. Post hoc analysis showed that males had significantly higher CPT reading scores than females. This interesting result is in contrast to a recent research study on college readiness where the differences between males and females in reading and math were examined. The study by Combs et al., 2010, which used SAT and ACT data from 1,009 high schools in Texas for the 2006-2007 school year, demonstrated "in reading, girls (51\%) had statistically significant higher rates of preparedness than did boys $(38.76 \%)$..." (p. 452). Conversely, results for math-readiness showed that "(52.57\%) [of boys] had statistically significantly higher rates of performance than did girls (44.12\%)" (Coombs et al., p. 452). Additionally, Coombs et al. examined the college readiness for math and reading in males and females and found that "during the 2006-2007 school year, 31.11\% of all high school graduates were college-ready in both reading and math. Girls $(32.38 \%)$ had higher rates of preparedness in both areas combined as compared to boys 30.19\%" (p. 452). One reason for the difference in results between the researcher's study and that of Combs et al.'s may be the differences in age groups; that is, this study used adult students versus 
high school students. In addition, Coombs et al. used the SAT and ACT, while the current research used the College Placement Test.

The results of the data analysis with respect to demographics also revealed group mean differences in CGPA, CPT Math, CPT Reading, and PGPA by ethnic origin. On the CPT Reading and Math scores, post hoc analysis revealed that the White group had higher mean scores than the African American group, while the Hispanic group had higher group mean scores than the Caribbean group. Although the White group only comprised $8 \%$ of the total, the fact that they scored higher on CPT Reading and Math is consistent with previous research (Combs et al., 2010), which found that Whites tended to outperform other ethnic groups in both math and science.

Studies related to nursing education and pass rates on the NCLEX-RN have also identified differences between ethnic groups. In particular, a study of an associate in science degree nursing program conducted by Powell, Sayles, and Shelton (2003) found that White students were more likely to pass the NCLEX-RN when compared to students from minority groups.

The logistic regression model predicted $81 \%$ of the cases correctly; however, the overall model was not statistically significant, showing that demographics (age, gender, and ethnicity) do not predict program completion with this group of participants.

Research Subquestion 3

Research Subquestion 3 asked to what degree does performance on the CPT predict program completion. For this subquestion, performance on the CPT Math had the highest impact on program completion. The logistic regression model predicted $79.7 \%$ of the cases correctly. In fact, the model indicated that students with a high CPT Math score 
were almost four times more likely to complete their program within the 2-year time frame prescribed by the program. This is not surprising given the analytical nature of medical laboratory science and mathematics, as well as the reality that critical thinking skills are required for both. Indeed, studies on the science of expert practice in medical laboratory science indicate that in order

to meet the challenges of today's increasingly varied and complex workplace, practitioners must become thinkers who know a great deal and continually adapt and refine, while they use their knowledge.... Success today requires new basics: the ability to reason, analyze, plan, and act effectively in a climate of change. This means practitioners of today must adjust for input that challenges their current thinking, and make appropriate, reasoned use of the understanding that develops. (Leibach, 2011, p. 438)

If the practitioner of the $21^{\text {st }}$ Century is to meet the challenges as described by Leibach (2011), then critical thinking may need to become the centerpiece of not only the curriculum in medical laboratory science, but also the other related science disciplines. In her research in clinical (medical) laboratory science (CLS), Leibach "operationalized the definition of critical thinking as a metaprocess that facilitates learning by interlinking the more basic processes associated with the different learning orientations: behaviorist, cognitivists, humanist, and situated/contextual learning" (p. 439).

\section{Research Subquestion 4}

Research Subquestion 4 asked to what degree does GPA (Cumulative GPA, Science GPA, and Professional GPA) predict program completion? Statistical analysis of 
the data again showed Professional GPA (PGPA) was the variable with the highest impact on completion of the academic program. The logistic regression model predicted $79.7 \%$ of the cases correctly. Additionally, the model indicated that students with a high Professional GPA were $\sim 3.5$ times more likely to complete the academic program within the prescribed 2 years. This is consistent with research in nursing (Alexander and Brophy, 1997; Jeffreys, 2007; Daley et al. 2003; Wong and Wong, 1999) where students with lower GPAs in their $1^{\text {st }}$ year nursing courses were found be at a higher risk of failure for the NCLEX-RN certification exam. Many of these researchers reporting on previous research indicated that lower specific GPAs in the nursing courses translated to decreased success on the NCLEX-RN. Studies with other programs such as physical therapy also found similar results. For example, Dockter (2001) examined the predictors of success on performance for the National Physical Therapy Exam (NPTE). For this study, Dockter used the GPAs after the second semester of the $1^{\text {st }}$ year in the program where it was found that "the best predictor of performance on the NPTE was the GPA after the first year of physical therapy school" (p. 62). While these studies do not tie Professional GPA to program completion, they do tie success on the credentialing examinations to success in the discipline-specific courses of the program of study, which are linked to GPA.

\section{Recommendations for Future Research}

As previously stated, the findings of this study indicate that Professional GPA is a potent predictor of completion for the Medical Laboratory Technology Program examined in this research. These findings are important to students and educators in the field of medical laboratory technology because PGPA is a new predictor examined in this discipline and one that can be used to provide early in-program intervention to the at-risk 
student, thus increasing the chances of successful timely completion. Campbell and Dickson (1996) indicated that there are multiple factors that affect a student's decision to leave college, but a major problem in student retention for nursing schools is related to student success. The same holds true for medical laboratory technology programs where retention and student success are problems that have been magnified with the increased diversity of the student population. Therefore, one recommendation would be to study more than one program and to include in that study programs in areas of the United States with different student populations. Additionally, the study did not explore other demographic factors such as socioeconomic or employment status. These are additional variables considered in Bean and Metzner's (1985) Conceptual Model of Student Attrition. Variables such as hours of employment and their impact on Professional GPA could shed light on some of the challenges faced by nontraditional students in medical laboratory technology programs.

Environmental variables such as family responsibilities and support might also be important for future research geared at determining predictors of success in medical laboratory technology A.S. degree programs. While previous studies in medical laboratory technology examined environmental factors such as study time, certainty of major, hours of employment, and support from friends (e.g., Laudicina, 1999), there needs to be more empirical research into these important areas to examine their possible associations with Professional GPA because students of the $21^{\text {st }}$ Century face ever pressing personal challenges that can translate into a decrease in the likelihood of program completion. 


\section{Limitations}

One of the limitations of this study is related to the population used, which consisted in large part of non-native English speakers typical of the type of student found in South Florida. South Florida has a diverse student population comprised primarily of White, Hispanic and African American students. At the college used in this study, 66.5\% of the students were Hispanic, and 35\% were more than 26 years old. In particular, the student population in the Medical Laboratory Technology program used in this study had a high percentage of not only Hispanics but also of Haitian students. Thus, the results of this study may not be applicable to more traditional student populations with limited or no representation from non-native English speakers and students of the more "traditional" college age, 18 to 20 years old.

There is another issue that may limit generalizations from this study. This research investigated the predictors of success in a 2-year A.S. degree program with a curriculum that includes courses on campus in the $1^{\text {st }}$ year and a half and a 4-month clinical experience at a hospital facility. Thus, the results of this study may have to be further investigated to determine their application to B.S. programs found in 4-year institutions with curriculums that include 3 years of on-campus coursework and 1 year of clinical experience in a hospital facility. Additionally, predictors of success found in universities with hospital-based programs may differ significantly from those found at the community college. Moreover, the data used in this study was a convenience sample from one institution and, therefore, may not be applicable to a larger population. 


\section{Implications for Future Practice}

The correlational analyses indicated that those who demonstrated higher CPGA, SGPA, and CPT-Math scores were more likely to complete their academic program within the two-year time span designed for the program. Thus, these are variables that can be used to identify at-risk students prior to starting the first semester. Thus, lower GPAs and CPT-Math scores are indicators of potential academic performance issues that can impact PGPA. Similar findings were also reflected with the ANOVA analyses in that those of different ethnic origins (i.e., Caribbean group) had lower group means in the CPGA, SGPA, CPT-Reading, and PGPA, suggesting preliminarily that there may be an issue of poorer high school preparation (e.g., being less likely to have attended a good school). Thus, instructors might address possible issues through proactively offering peer tutoring or structured learning assistance in their first semester in program.

Second, Professional GPA was a significant predictor of program completion; therefore, it can be used to identify at-risk students and initiate remediation early in the program. This remediation may take different forms and can range from targeted tutoring to use of computer software to taking a closer look at the curriculum and identifying areas where critical thinking can be further infused in the curriculum. Curriculum enhancements may take the form of cooperative projects with math and science professors to identify areas where critical thinking can be emphasized in the student prior to starting the medical laboratory technology program. Targeted tutoring could be useful as well to support course-specific issues, such as poor performance on hematology laboratory or laboratory mathematics and quality control. 


\section{Conclusion}

This study addressed the problem of attrition in an A.S. degree medical laboratory technology program by examining academic predictors of success. The results of this study are clear in that Professional GPA is significant in determining completion of the academic program within the prescribed two years.

While more research into the variables that contribute to attrition is warranted, it is clear from the literature on the shortages of clinical laboratory professionals, the Bureau of Labor Statistics projected needs for the next 5 years, and the facts regarding the aging population that recruiting and maintaining qualified candidates in medical laboratory technology programs will take center stage in the years to come. It is also clear from the literature on shortages that the numbers of programs we have cannot keep up with the pace of professionals needed within the next 5 years given the retirement projections for the profession. Therefore, it is incumbent on educators and researchers to continue conducting empirical studies that examine the predictors of program completion and to make the appropriate changes in curriculum and student interventions based on this research that can translate into increasing the likelihood of timely program completion. 


\section{References}

Alexander, J. E., \& Brophy, G. H. (1997). A five-year study of graduates' performance on NCLEX-RN. Journal of Nursing Education, 36, 443-445.

American Society for Clinical Pathology (2009). Survey results point to worsening scenario for laboratory workforce. ePolicy News.

Bauchmeyer S. M., Carr, M. P., Clutter, J. E., Hoberty, P. D. (2004). Predicting academic and national board dental hygiene examination performance based on academic factors. Journal of Dental Hygiene, 78, 39-45.

Bean, J. (1980). Dropout and turnover, the synthesis and test of a causal model of student attrition. Research in Higher Education, 12, 155-187.

Bean, J. P., \& Metzner, B. S. (1985). A conceptual model of nontraditional undergraduate student attrition. Review of Educational Research, 55(4), 485-540.

Boughan, K. (1998). New approaches to the analysis of academic outcomes: Modeling student performance at a community college. Paper presented at the Annual Forum of the Association of Institutional Research, Minneapolis, MN. (ERIC Document Reproduction Service No. ED424798)

Bugbee, A. C. (2007). ASCP Board of registry's 2006 annual survey of medical laboratory science programs. Labmedicine, 28(8). 463-471.

Burns, R., Burns, R. (2009). Logistic regression. Business research methods and statistics using SPSS. Retrieved April 21, 2012 from http://www.uk.sagepub.com/burns/contents.htm

Cabrera, A. F., Castaneda, M. B., Nora, A., \& Hengstler, D. (1992). The convergence between two theories of college persistence. Journal of Higher Education, 63(2), 143-164. Retrieved August 16, 2007, from JSTOR.

Campbell, A. R., \& Dickson, C. J. (1996). Predicting student success: A 10-year review using integrative review and meta-analysis. Journal of Professional Nursing, 12(1), 47-59.

Combs, J. P., Slate, J. R., Moore, G. W., Bustamante, R. M., Onwuegbuzie, A. J., Edmonson, S. L. (2010). Gender differences in college preparedness: A statewide study. Urban Review, 42(5), 441-457.

Crosnoe, R., Mistry, R., \& Elder, Jr., G. (2002). Economic disadvantage, family dynamics, and adolescent enrollment in higher education. Journal of Marriage and Family, 64. Retrieved April 21, 2012, from JSTOR. 
Daley, L. K., Kirkpatrick, B. L., Frazier, S. K., Chung, M. L., \& Moser, D. K. (2003). Predictors of NCLEX-RN success in a baccalaureate nursing program as a foundation for remediation. Journal of Nursing Education, 42(9), 390-398.

DeMaris, A., (1995). A tutorial in logistic regression. Journal of Marriage and Family, 57(4). Retrieved April 21, 2012, from JSTOR.

Dockter, M. (2001). An analysis of physical therapy preadmission factors on academic success and success on the national licensing examination. Journal of Physical Therapy Education, 15(1), 60-64.

Downey, M. C., Collins, M. A., \& Browning W. D. (2002). Predictors of success in dental hygiene education: A six-year review. Journal of Dental Education, 66(11), 1269-1273.

Downing, S. A., Mann, J. D., \& Tomlinson, S. M. (1982). The effect of academic preparation on medical technologists' registry examination performance. American Journal of Medical Technology, 48(12), 1005-1009.

Elder, Jr. O. C., Nick, T. D., \& Fowler, D. G. (1997). Important curriculum considerations for baccalaureate programs in clinical laboratory science. Clinical Laboratory Science, 10(1), 27-31.

Enrado, P. (2009, May). Closure of clinical lab sciences programs threatens healthcare industry. Healthcare Finance News. Retrieved June 15, 2012, from http://www.healthcarefinancenews.com

Ferguson, E., James, D., \& Madeley, L. (2002). Factors associated with success in medical school: Systematic review of the literature. British Medical Journal, 324, 952-957. Retrieved June 18, 2008, from ProQuest

Goodyear, N., \& Lampe M. F. (2004). Standardized test scores as an admission requirement. Clinical Laboratory Science, 17(1), 19-24.

Hilborne, L. H. (2008). ASCP battles workforce shortage on many fronts. Critical Values, $1(4), 7-9$.

Holladay, E. B., Kinney, M. C., Bernstein, B. D., Duncan, C., Wilkinson, S. L. (2008, Spring/Summer). ASCP board of registry celebrates $80^{\text {th }}$ anniversary: Around the world in 80 years - BOR Newsletter. Retrieved March 24, 2012, from http://www.ascp.org/PDF/BOC-PDFs/News/Newsletter/BORNewsletter.aspx

Hopkins, T. H. (2008). Early identification of at-risk nursing students: A student support model. Journal of Nursing Education, 47(6), 254-259. 
Houltram, B. (1996). Entry age, entry mode and academic performance on a Project 2000 common foundation programme. Journal of Advanced Nursing, 23, 1089-1097.

Jeffreys, M. R. (2002). Students' perceptions of variables influencing retention. Nurse Educator, 27, 16-19.

Jeffreys, M. R. (2007). Tracking students through program entry, progression, graduation, and licensure: Assessing undergraduate nursing student retention and success [Electronic version]. Nurse Education Today, 27, 406-419.

Kirby, B. A. (2007). The future of clinical laboratory science: A Delphi study. (West Virginia University, Morgantown, WV). ProQuest Dissertations and Theses, http://search.proquest.com.ezproxy.fiu.edu/docview/304798641/fulltextPDF/1377 4F3D7167FD3857C/1?accountid=10901

Kotlarz, V. R. (1998). Tracing our roots: Origins of clinical laboratory science. Clinical Laboratory Science, 11(1), 5-7.

Kudlas, M. J. (2006). Effects of radiography program admissions practices on student retention. Journal of Allied Health, 35, 162-168. Retrieved June 18, 2008, from ProQuest Nursing \& Allied Health Source.

Lanier, R. A., \& Lambert, N. T. (1981). Predicting academic performance in medical technology: A university-based program in retrospect. American Journal of Medical Technology, 47(5), 314-319.

Lanni, J. C. (1997). Modeling student outcomes: A longitudinal study (Report No. HE030466). Orlando, FL: Thirty-Seventh Annual Forum of the Association for Institutional Research. (ERIC Document Reproduction Service No. ED410870)

Laudicina, R. J. (1999). Characteristics of clinical laboratory technician students and effects on program outcome. Clinical Laboratory Science, 12(4), 221-225.

Leibach, E. K. (2011). Grounded theory in medical laboratory science expert practice development. Supplement Clinical Laboratory Science, 24, 437-444.

Lewis, C., \& Lewis, J. H. (2000). Predicting academic success of transfer nursing students. Journal of Nursing Education, 39(5), 234-236. Retrieved March 15, 2008, from Wilson Web database.

Mattern, K., \& Packman, S. (2009). Predictive validity of ACCUPLACER (C) scores for course placement: A meta-analysis. College Board Research Report No. 2009-2. Retrieved January 30, 2010, from College Board Web site:

http://www.collegeboard.com 
McCall, K. L., Allen, D. D., \& Fike, D. S. (2006). Predictors of academic success in a doctor of pharmacy program. American Journal of Pharmaceutical Education, 70(5), $1-7$.

Metz, G. W. (2000). Challenges and changes to Tinto's persistence theory Paper presented to Mid Western Educational Research Association, Columbus, OH. (ERIC Document Reproduction Service No. ED471529)

Miami Dade College Fact Book (2012). Retrieved June 21, 2012, from http://www.mdc.edu/ir/Fact\%20Book/MDC\%20Highlights\%20and\%20Facts_Jan uary\%202012.pdf

Miami Dade College, Florida College Entry-Level Placement Test, (September 9, 2008). Retrieved July 10, 2009 from https://www.mdc.edu/testing_information/CPT_CLAST/01-936.pdf

Miami Dade College, Miami, Institutional Research. (2008, September). Enrollment history by term and academic year 2007-2008. Retrieved November 20, 2008, from the Institutional Research Web site: http://www.mdc.edu/ir/hcandcreds.htm

Miami Dade College Placement Criteria for Academic Year 2009-2010, (June 3, 2009). Retrieved July 10, 2009, from http://www.mdc.edu/ir/CPT_CLAST/Placement_Document_2009-2010.pdf

Miami Dade College About MDC (n.d.). Retrieved June 20, 2012, from http://www.mdc.edu/main/about/facts_in_brief.aspx

Murtaugh, P., Burns, L. D., \& Schuster, J. (1999). Predicting the retention of university students. Research in Higher Education, 40(3), 355-371.

Negelkerke, N. J. D., (1991). A note on a general definition of the coefficient of determination. Biometrika, 78(3). Retrieved April 21, 2012, from JSTOR.

Newton, S. E., Smith, L. H., Moore, G., \& Magnan, M. (2007). Predicting early academic achievement in a baccalaureate nursing program. Journal of Professional Nursing, 23(3), 144-149.

Newman, M., \& Williams, J. (2003). Educating nurses in Rhode Island: A lot of diversity in a little place. Journal of Cultural Diversity, 10(3), 91-95.

Pascarella, E. T., \& Terenzini, P. T. (1980). Predicting freshman persistence and voluntary dropout decisions from a theoretical model. Journal of Higher Education, 51(1), 60-75. 
Pascarella, E. T., Duby, P. B., \& Iverson, B. K. (1983). A test and reconceptualization of a theoretical model of college withdrawal in a commuter institution setting. Sociology of Education, 56, 88-100.

Potolsky, A., Cohen, J., \& Saylor, C. (2003). Academic performance of nursing students: Do prerequisite grades and tutoring make a difference? Nursing Education Perspectives, 24(5), 246-250.

Powell, H., Sayles, S., \& Shelton, D. (2003). Predictors of success in nursing education. ABNF Journal, 14(6), 116. Retrieved May 26, 2012, from Academic OneFile database.

Reason, R. D. (2003). Student variables that predict retention: Recent research and new developments. NASPA Journal 40(4), 172-191.

Rodriguez, F. H., \& Ball, J. R. (2007). The American Society for Clinical Pathology: The pathology society of "firsts". LABMEDICINE. 38(10), 595-601.

Rogulkin, D. (2011). Predicting 6-year graduation and high achieving and at-risk students. Fresno, California: California State University, Institutional Research Department.

Smith, T. D. (2010). Asian American/European American and Latino/a/European American multiracial psychology students in higher education: Academic barriers, academic supports, perceptions of cultural diversity, and experiences. University of Maryland, Baltimore County). ProQuest Dissertations and Theses, http://search.proquest.com/docview/757004563? accountid=10901

Spady, W. (1970). Dropouts from higher education: An interdisciplinary review and synthesis. Interchange 1, 64-85.

Stewart, C. A., Thompson, N. N. (2006). ASCP 2005 wage and vacancy report survey of medical laboratories. Labmedicine, 37(8), 465-469.

Stickney, M. C. (2008). Factors affecting practical nursing attrition. Journal of Nursing Education, 47(9), 422-425.

Steyerberg, E. W., Vickers, A. J., Cook, N. R., Gerds, T., Gonen, M., Obuchowski, N., et al. (2010). Assessing the performance of prediction models a framework for traditional and novel measures. Epidemiology, 21, 128-137.

Summers, M. D. (2003). Attrition research at community colleges. Community College Review, 30, 64-84. Retrieved March 15, 2008, from Wilson Web database. 
Tabachnick, B. G. \& Fidell, L. S. (2001). Using multivariate statistics (4th ed.). Boston: Allyn and Bacon.

Texas Education Agency. (2007). Snapshot 2007 school district profiles. Retrieved May 28, 2012 from http://ritter.tea.state.tx.us/perfreport/snapshot/

Tinto, V. (1975). Dropout from higher education: A theoretical synthesis of recent research. Review of Educational Research, 45(1), 89-125.

Tinto, V. (1988). Stages of student departure: Reflections on the longitudinal character of student leaving. The Journal of Higher Education, 59, 438-455. Retrieved July 14, 2007, from JSTOR archive.

Tinto, V. (1997). Classrooms as communities: Exploring the educational character of student persistence. The Journal of Higher Education, 68, 599-623. Retrieved June 15, 2012, from JSTOR archive.

Tinto, V. (1998). Colleges as communities: Taking research on student persistence seriously [Electronic version]. The Review of Higher Education, 21.2, 167-177.

U.S. Census Bureau, Population Division. (2005, April). Interim state population projections, 2005. Retrieved August 15, 2008, from http://www.census.gov/population/www/projections/statepyramid.html

U.S. Department of Labor, Bureau of Labor Statistics. (n.d.). Occupational outlook handbook, 2008-2009. Retrieved January 21, 2008, from http://www.bls.gov/oco/ocos096.htm

U.S. Department of Education, National Center for Education Statistics. (n.d.). Education Statistics Quarterly, 4(3). Retrieved August 20, 2008, from http://nces.ed.gov/programs/quarterly/Vol_4/4_3/4_1.asp

U.S. Department of Labor, Bureau of Labor Statistics. (n.d.). Occupational outlook handbook, 2012. Retrieved May 19, 2012, from http://www.bls.gov/ooh/healthcare/medical-and-clinical-laboratory-technologistsand-technicians.htm

Wharrad, H., Chapple, M., \& Price, N. (2003). Predictors of academic success in a bachelor of nursing course. Nurse Education Today, 23, 246-254.

Wiggers, T. B., \& Holton, R. H. (2001). Predictive value of a senior comprehensive examination as to performance on a national certification examination. Clnical Laboratory Science, 14(1), 21-26. 
Wong, J., \& Wong, S. (1999). Contribution of basic sciences to academic success in nursing education. International Journal of Nursing Studies, 36, 345-354.

Yang, N. (1997). The rising learning age: Benefits and challenges of increased nontraditional students in higher education. Allied Academies International Conference 1997 Academy of Educational Leadership Proceedings, 2(2), 4-7. Retrieved from http://search.proquest.com/docview/192407791?accountid=10901

Ying, C., Peng, J., Lee, K. L., Ingersoll, G. M., (2002). An introduction to logistic regression analysis and reporting. The Journal of Educational Research 96, 3-14. 
VITA

Nilia M. Madan

1976

B. S., Medical Technology

Florida International University

Miami, Florida

1976

Medical Technologists License

Florida Department of Health

1977

Medical Technologist Certification

American Society for Clinical Pathologists

1980

Clinical Laboratory Supervisor License

Florida Department of Health

1990

Master, Business Administration

Nova Southeastern University

Ft. Lauderdale, Florida

1993 - Present

CLS Program Coordinator

Miami Dade College

Miami, Florida

2003

Specialist in Hematology Certification

American Society for Clinical Pathology

2003-2012

Doctoral Candidate

Florida International University

Miami, Florida

HONORS, AWARDS, AND PRESENTATIONS

2007

William N. Reich Outstanding Achievement Award American Association of Bioanalysts

2007- Present

Board Member

Florida Board of Clinical Laboratory Personnel

2011

Outstanding Speaker Award

American Association of Clinical Chemistry 